\title{
Review:
}

\section{The membrane interactions of antimicrobial peptides revealed by solid- state NMR spectroscopy}

\author{
Burkhard Bechinger* and Evgeniy S. Salnikov
}

${ }^{1}$ Université de Strasbourg / CNRS, UMR7177, Institut de Chimie, 4, rue Blaise Pascal, 67070 Strasbourg, France

* corresponding author: Burkhard Bechinger

Faculté de chimie, Institut le Bel, 4, rue Blaise Pascal, 67070 Strasbourg, France Tel.: +33 3688551 50, FAX: +33 3688551 51, bechinger@ unistra.fr

Key words : magainin; PGLa; cecropin; pardaxin; alamethicin; peptaibol; supported membranes; uniaxially oriented bilayers; membrane topology; hydrophobic mismatch; inplane orientation; transmembrane alignment; peptide-lipid interactions; aurein; distinctin; membrane pore; membrane macroscopic phase; molecular shape concept; lipid disorder; membrane disruption; detergent; carpet model; torroidal pore; synergism; dynamics

Running title : Solid-state NMR of antimicrobial peptides 


\begin{abstract}
Solid-state NMR spectroscopic techniques provide valuable information about the structure, dynamics and topology of membrane-inserted polypeptides. In particular antimicrobial peptides (or 'host defense peptides') have early on been investigated by solid-state NMR spectroscopy and many technical innovations in this domain have been developed with the help of these compounds when reconstituted into oriented phospholipid bilayers. Using solidstate NMR spectroscopy it could be shown for the first time that magainins or derivatives thereof exhibit potent antimicrobial activities when their cationic amphipathic helix is oriented parallel to the bilayer surface, a configuration found in later years for many other linear cationic amphipathic peptides of this class. In contrast transmembrane alignments or lipid-dependent tilt angles have been found for more hydrophobic sequences such as alamethicin or $\beta$-hairpin antimicrobials. This review presents various solid-state NMR approaches and develops the basic underlying concept how angular information can be obtained from oriented samples. It is demonstrated how this information is used to calculate structures and topologies of peptides in their native liquid-disordered phospholipid bilayer environment. Special emphasis is given to discuss which NMR parameters provide the most complementary information, the minimal number of restraints needed and the effect of motions on the analysis of the NMR spectra. Furthermore, recent ${ }^{31} \mathrm{P}$ and ${ }^{2} \mathrm{H}$ solid-state NMR measurements of lipids are presented including some unpublished data which aim at investigating the morphological and structural changes of oriented or non-oriented phospholipids. Finally the structural models that have been proposed for the mechanisms of action of these peptides will be presented and discussed in view of the solid-state NMR and other biophysical experiments.
\end{abstract}


Abbreviations used:

Aib $\quad \alpha$-aminobutyric acid

ATR-FTIR attenuated total reflection Fourier transform infra-red

$B_{0} \quad$ magnetic field of the NMR spectrometer

DHPC 1,2-dihexanoyl-sn-glycero-3-phosphocholine

DLPC 1, 2-dilaureoyl-sn-glycero-3-phosphocholine

DMPC 1,2-dimyristoyl-sn-glycero-3-phosphocholine

DMPG 1, 2-dimyristoyl-sn-glycero-3-phospho-(1'-rac-glycerol)

DOPC 1, 2-dioleoyl-sn-glycero-3-phosphocholine

DMPG 1, 2- dioleoyl-sn-glycero-3-phospho-(1'-rac-glycerol)

DPPC 1, 2-dipalmitoyl-sn-glycero-3-phosphocholine

LPS lipopolysaccaride

MAS magic angle spinning

NMR nuclear magnetic resonance

PC 1, 2-diacyl-sn-glycero-3-phosphocholine

PE 1, 2-diacyl-sn-glycero-3-phosphoethanolamine

PG 1, 2-diacyl-sn-glycero-3- phospho-(1'-rac-glycerol)

PS 1, 2-diacyl-sn-glycero-3-phosphoserine

POPC 1-palmitoyl-2-oleoyl-sn-glycero-3-phosphocholine

POPE 1-palmitoyl-2-oleoyl-sn-glycero-3-phosphoethanolamine

POPG 1-palmitoyl-2-oleoyl-sn-glycero-3-phospho-(1'-rac-glycerol)

r.h. relative humidity

TM transmembrane 


\section{Antimicrobial peptides}

Biophysical investigation of the mechanisms of action of naturally and designed antimicrobial compounds are performed in order to develop new and better pharmaceuticals in a world where the increasing antibiotic resistance of pathogens imposes serious challenges to human health (Savjani et al., 2009; Vooturi and Firestine, 2010). Many antibiotic peptides have indeed been discovered in plants (Benko-Iseppon et al., 2010; Padovan et al., 2010) and animals (Bulet et al., 2004; Reddy et al., 2004) and the importance of the subject has been underlined by awarding the most recent Nobel prize in medicine to discoveries related to the innate and adaptive immune system, with the peptides being part of the former. A wide variety of antimicrobial peptides are produced when infections occur and/or are stored in exposed tissues of animals and plants, thereby, establishing a first line of defence that is fast and efficient (Boman, 2003; Zasloff, 2002). As these peptides are not only able to selectively kill bacterial and fungal cells but also to exhibit immunomodulatory functions reference is often made to 'host defence peptides' (Diamond et al., 2009; Holzl et al., 2008; Steinstraesser et al., 2010). In order to develop more easy to produce and / or more potent analogues the mechanisms of action of their bacteriocidal and fungicidal activities need to be understood such that the naturally occurring molecules or derivatives thereof, can serve as a templates for drug development (Hadley and Hancock, 2010; Kindrachuk and Napper, 2010; Liu et al., 2010; Oyston et al., 2009; Romo et al., 2011; Schweizer, 2009; Scott et al., 2008). To this end structure-function studies are performed including biophysical and solid-state NMR spectroscopy investigations (Bechinger, 1997; Duclohier, 2010; Gregory et al., 2008; Haney et al., 2009; Hwang and Vogel, 1998; Kindrachuk and Napper, 2010).

Magainins and cecropins, antimicrobial peptides from frogs and insects, respectively, were early on discovered and are probably the peptides that have been investigated most thoroughly (Boman and Hultmark, 1987; Giovannini et al., 1987; Hoffmann et al., 1983; Kiss and Michl, 1962; Zasloff, 1987). The amino acid sequences of these and other peptides discussed in this review are listed in Table 1 . These cationic linear peptides not only exhibit a broad-range of antimicrobial but also virucidal, spermicidal and anti-cancer activities (Dennison et al., 2006; Mader and Hoskin, 2006; Reddy et al., 2004; Schweizer, 2009; Zairi et al., 2009; Zhang and Falla, 2010).

Due to their cationic nature magainins, cecropins and related sequences are attracted by negatively charged surfaces including model membranes or the outer layers of bacteria (Matsuzaki et al., 1999; Wieprecht et al., 2000). The peptides have been shown to interact 
with the membranes in subsequent steps where they adopt amphipathic, often $\alpha$-helical, conformations (Bechinger, 1999; Beevers and Dixon, 2010; Fernandez et al., 2009; Georgescu and Bechinger, 2010; Giuliani et al., 2008; Gottler and Ramamoorthy, 2009; Haney et al., 2009; Zasloff, 2002). Thereby they disrupt the bilayer integrity, increase the flow of ions across the membranes and concomitantly cause the collapse of the transmembrane electrochemical gradients (Bolintineanu et al., 2010; Pieters et al., 2009) and deprive the affected organisms of their source of energy (Westerhoff et al., 1989).

A number of molecular models have been established with the aim to explain the pore forming and antimicrobial properties of these cationic amphipathic peptides (Bechinger, 1999). The contributions of solid-state NMR spectroscopy to develop a better understanding how these peptides function will be outlined in this paper thereby extending previous reviews in the field (Bechinger, 2011; Ramamoorthy, 2009). The functional modes of action that have been suggested to exist include torroidal pores formed by a supramolecular assembly of peptides and lipids and characterized by regions of high curvature (Ludtke et al., 1996; Matsuzaki, 1998). Furthermore, the 'carpet model' is based on the accumulation of high concentrations of peptides at the membrane which causes membrane disintegration (Shai, 1999). Notably in the latter case the amphipathic structures align parallel to the surface and this arrangement also applies to a third model which explains the transient and step-wise formation of membrane openings, that have been observed experimentally at much lower concentration, by diffusion-related stochastic fluctuations in the density of in-planar peptides (Bechinger, 1999). Finally by taking into consideration the soft and flexible nature of membrane supramolecular assemblies all these different arrangements have been reunified into a phase diagram (Bechinger, 1999, 2009; Bechinger and Lohner, 2006). More recent evidence also points to the existence of intracellular targets, at least for some of the antimicrobial sequences, but also in this case the peptides have to cross the membranes of the bacterial, fungal or cancer cells (for reviews see (Brogden, 2005; Dennison et al., 2006; Mader and Hoskin, 2006; Nicolas, 2009; Schweizer, 2009)).

Here focus will be given to the study of predominantly helical antimicrobial and related peptides using solid-state NMR spectroscopy. For comparison we will also report shortly on solid-state NMR investigations on amphipathic peptides adopting a $\beta$-hairpin (Hong and $\mathrm{Su}, 2011$ ) as well as peptaibols, amphipathic peptides that derive their name from the high abundance of $\alpha$-aminobutyric acid (Aib) and that carry no or only few charges. These peptides belong to a different class of antimicrobial peptides and are produced in nature 
by fungal cells (Leitgeb et al., 2007). In contrast to magainins and related peptides these much more hydrophobic sequences have early on considered as a paradigm for the formation transmembrane helical bundles similar to large channel proteins (Bechinger, 1997; Sansom, 1993). Notably, recent results suggest considerable plasticity of these peptides and their assemblies are probably less well organized than has been suggested before (Salnikov et al., 2009b; Thogersen et al., 2008).

\section{Solid-state NMR spectroscopy for the investigations of the structure, dynamics and topology of membrane-associated peptides}

The structural investigation of membrane proteins and peptides remains a challenging task as they are often difficult to prepare in quantitative amounts and to solubilise under conditions that are relevant to their physiological environment. Furthermore, peptides that associate with membranes exhibit a large conformational space where they exhibit random coil conformations in aqueous solution and the relevant structures are only induced by interactions with membranes. This is an important aspect when it comes to choose the most suitable method for their structural investigation. For example, whereas the crystal structures of such peptides are dominated by peptide-peptide interactions NMR techniques allows for their investigations in membrane environments at ambient and physiological temperatures.

On the one hand multidimensional solution NMR spectroscopy is a well-established technique to determine the structure of globular proteins in isotropic environments and the investigation of membrane-associated polypeptides can be achieved by their reconstitution into relatively small micellar or bicellar complexes (Columbus et al., 2009; Gautier et al., 2010; Renault et al., 2010). On the other hand solid-state NMR spectroscopy is probably the only high-resolution technique where these peptides can be studied in the presence of liquid disordered phospholipid bilayers. Importantly NMR spectroscopy can be applied to investigate both the peptide structure, dynamics, topology and aggregation (Baldus, 2006; Bechinger and Sizun, 2003; Cross, 1997; Davis and Auger, 1999; Lange et al., 2010; Traaseth et al., 2009; Watts, 2005) but also the conformational and overall supramolecular characteristics of the lipid-peptide assemblies. Furthermore, the detailed order parameter of the lipid fatty acyl chains (Cullis and De Kruijff, 1979; Drechsler et al., 2010; Dufourc, 2008; Salnikov et al., 2009c; Seelig, 1977; Thennarasu et al., 2010) or the separation of lipid domains due to the presence of polypeptides has been characterized using solid-state NMR 
spectroscopy (Epand et al., 2010; Mason et al., 2006). Notably, ${ }^{31} \mathrm{P}$ solid-state NMR spectroscopy has recently been used to study the effects of a $\beta$-sheet antimicrobial peptides on a lipopolysaccaride / phosphatidylethanolamine mixture, i.e. a mimic of the outer membrane of Gram-negative bacteria (Su et al., 2011) thereby complementing previous studies using lipid compositions which reproduce the cytoplasmic membranes. A detailed phase diagram was also established for DOPE/DOPG lipid mixtures including the effects of several synthetic amphiphilic antimicrobial oligomers on the phase boundaries (Hu et al., 2011).

To understand the principles and concepts of solid-state NMR spectroscopy one should be aware that most NMR interactions are strongly dependent on the alignment of molecules relative to the magnetic field direction $\left(\mathrm{B}_{\mathrm{o}}\right)$. In solution these anisotropies are averaged by fast rotational diffusion and only the residual isotropic contributions are observed. In contrast NMR spectra of solid or semi-solid samples, or of molecules or molecular complexes that are large and tumble slowly the chemical shifts, dipolar and quadrupolar interactions are all anisotropic and in static samples broad powder patter line shapes are observed. As a consequence the spectral resonances from individual sites tend to overlap. In order to reintroduce well-resolved spectra two fundamentally different approaches have been established, namely fast spinning around the magic angle (MAS), which mechanically averages the orientation-dependent NMR interactions, or the uniaxial alignment of the samples relative to the magnetic field direction. These methods result in relatively narrow line shapes also of proteins in the solid state or when associated with lipid bilayers. A critical parameter to obtain highly resolved MAS solid-state spectra is to prepare samples that exhibit a high degree of local order (Pauli et al., 2000). In such cases multidimensional high-resolution MAS solid-state NMR spectra have been used to extract angular and distance constraints for protein structure determination, which follows strategies that have already been established for biomacromolecules in solution (Andronesi et al., 2005; Baldus, 2006; Bockmann, 2008; Castellani et al., 2002; McDermott, 2009; Nielsen et al., 2009; Nieuwkoop and Rienstra, 2010; Schuetz et al., 2010).

By using MAS solid-state NMR membrane-inserted potassium channels (Ader et al., 2010; Schneider et al., 2008; Varga et al., 2007), ABC transporters (Lange et al., 2010), outer membrane proteins (Hiller et al., 2008), sensory rhodopsin II (Etzkorn et al., 2010), phospholamban (Seidel et al., 2008), and the drug binding site within a peptide domain extracted from the Influenza proton channel (Cady et al., 2010) have been characterized. Furthermore, isotopically labelled ligands have been studied when associated with non-labelled membrane receptors (Krabben et al., 2009; Luca et al., 2003; Williamson et al., 2002). Various MAS solid-state NMR techniques have also been applied to investigate the conformational 
properties, aggregation, peptide-lipid contacts and water accessibility of antimicrobial peptides when interacting with membranes, in particular several $\beta$-sheet antimicrobial peptides have been characterized in this manner (Su et al., 2011; Tang and Hong, 2009). Furthermore, the conformation of lipids and their interactions with polypeptides or other additives have been investigated using MAS solid-state NMR spectroscopy (Gawrisch et al., 2002). Another interesting line of research using MAS solid-state NMR spectroscopy is the investigation of the differential effects of antibiotics on the cell wall of Enterococcus faecium (Patti et al., 2009) or the response in situ of the mitochondrial lipids to apoptotic-like stress (Sani et al., 2009).

\section{Analysis of the peptide structure and topology by ${ }^{15} \mathrm{~N}$ and ${ }^{2} \mathrm{H}$ solid-state NMR spectroscopy}

Besides solution and MAS solid-state NMR spectroscopies, which are conceptually related, a third and complementary solid-state NMR method uses uniaxially oriented membranes. The approach takes advantage of the orientation-dependence of NMR interactions and will be the focus of this review. As most of the NMR measureables exhibit a strong dependence as to their alignment relative to the magnetic field direction angular restraints can be extracted from such samples. This information enables an alternative and highly complementary approach to calculate structures and also the topologies of membrane-associated polypeptides (Bechinger and Sizun, 2003; Cross, 1997). It is thus necessary to reconstitute the polypeptides into lipid bilayers that are uniaxially oriented with respect to the magnetic field direction and this method has initially been developed on antimicrobial peptides such as gramicidin A (Cross, 1997), magainins (Bechinger et al., 1993) and related peptides (Chekmenev et al., 2006; Gottler and Ramamoorthy, 2009; Mason et al., 2007; Resende et al., 2009; Salnikov et al., 2009b; Sugewara et al., 2009). In the meantime it has also been shown highly successful in the structural analysis of the bilayer-spanning sequences $\mathrm{Vpu}$, alamethicin and phospholamban (North et al., 1995; Salnikov et al., 2009b; Thogersen et al., 2008; Traaseth et al., 2009; Wray et al., 1999), and finally more and more solid-state NMR investigations on larger membrane proteins in oriented bilayers emerge (e.g. (Aisenbrey et al., 2009; Aisenbrey et al., 2007; Vosegaard et al., 2008)).

A prerequisite for the calculation of angular restraints from solid-state NMR spectra is the detailed knowledge of the size of the interactions of nuclei with the magnetic field as well as their angular correlations. Therefore, the interaction tensors of a number of biologically interesting nuclei have been characterized including, for example, the ${ }^{15} \mathrm{~N}$ chemical shift 
interaction of peptide bonds (recently reviewed in (Salnikov et al., 2009a)). To illustrate the degree of anisotropy of these interactions it should be mentioned that ${ }^{15} \mathrm{~N}$ chemical shift interaction is characterized by an anisotropy of about 170 ppm which exceeds by an order of magnitude the ${ }^{15} \mathrm{~N}$ chemical shift dispersion typically observed for proteins in solution (Bechinger and Sizun, 2003). The chemical shift $\sigma_{\mathrm{zz}}$ is calculated according to $\sigma_{\mathrm{zz}}=\sigma_{11} \sin ^{2} \Theta$ $\cos ^{2} \Phi+\sigma_{22} \sin ^{2} \Theta \sin ^{2} \Phi+\sigma_{33} \cos ^{2} \Theta$, where $\sigma_{11}, \sigma_{22}$ and $\sigma_{33}$ are the main tensor elements, and $\Theta$ and $\Phi$ the Euler angles which position the chemical shift tensor relative to $B_{o}$. For example, the tensor of the ${ }^{15} \mathrm{~N}$ amide bond is characterized by the tensor elements 55, 80, and $225 \mathrm{ppm}( \pm 5 \mathrm{ppm})$ and the alignment of these vectors relative to the molecular coordinate system is described in detail in the literature (reviewed in (Salnikov et al., 2009a)).

Furthermore, the dipolar coupling is calculated according to $D z z=\frac{\mu_{o}}{4 \pi} \frac{\gamma_{1} \gamma_{2} \mathrm{~h}}{r^{3}}\left(3 \cos ^{2} \Theta-1\right)$, where $r$ is the distance between the two interacting nuclei and $\Theta$ the angle between the distance vector and $B_{0}$. The dipolar coupling constant $\frac{\mu_{o}}{4 \pi} \frac{\gamma_{1} \gamma_{2} \mathrm{~h}}{r^{3}}$ is dependent on the magnetogyric ratios $\gamma_{1}$ and $\gamma_{2}$ of the two interacting nuclear dipoles, and $\mu_{\mathrm{o}}$ represents the free magnetic inductivity. When changing the orientation of the dipolar interaction vector $\Theta$ relative to $B_{o}$ the dipolar interaction of the ${ }^{1} \mathrm{H}-{ }^{15} \mathrm{~N}$ pair of the amide bond covers values between $-20 \mathrm{kHz}$ and $10 \mathrm{kHz}$ (detailed in (Bechinger and Sizun, 2003)).

In addition, two common applications using the deuterium quadrupolar splitting are described in this review. On the one hand deuteration of the methyl group of alanines has proven useful for the analysis of the secondary structure and topology for membrane-inserted peptides as the methyl group is directly connected with the peptide backbone and the $\mathrm{C} \alpha-\mathrm{C} \beta$ bond exhibits a well-defined alignment relative to the helix long axis $\left(59.4^{\circ}\right.$, cf. reference (Vostrikov et al., 2010)). Due to fast rotation around this bond the three deuterons are equivalent at ambient temperatures (Batchelder et al., 1983) and a single intensity is recorded from the three sites. As a consequence the static quadrupolar tensor is averaged by a factor of 3 (cf. below) and the resulting average aligned parallel to the $\mathrm{C} \alpha-\mathrm{C} \beta$ bond. The quadrupolar interaction is $\Delta v_{Q}=\frac{3}{2}\left(\frac{e^{2} q Q}{3 h}\right)\left(\frac{3 \cos ^{2} \Theta-1}{2}\right)$, with $\Theta$ being the angle between the $\mathrm{C} \alpha-\mathrm{C} \beta$ bond and $\mathrm{B}_{\mathrm{o}}$. The static quadrupolar coupling constant $\frac{e^{2} q Q}{h}$ has been determined to be $167 \mathrm{kHz}$ for aliphatic C- ${ }^{2} \mathrm{H}$ bonds (Batchelder et al., 1983; Davis, 1983). However, when room temperature deuterium solid-state NMR spectra are recorded of dry peptide powders that contain $\mathrm{C}-{ }^{2} \mathrm{H}_{3}$-alanine or of $\mathrm{C}_{-}^{2} \mathrm{H}_{3}$-labeled Plexiglas maximum splittings of $\sim 74 \mathrm{kHz}$ are 
observed (instead of expected value of $\sim 84 \mathrm{kHz}$ ), which indicates additional averaging by internal motions of the deuterated sites. More recently investigations using ${ }^{14} \mathrm{~N}$, another quadrupolar nucleus, have also been presented (Ramamoorthy et al., 2008).

Each of the above listed solid-state NMR measureables provides information to restrict the possible spatial alignment of the backbone atoms relative to the magnetic field direction $\left(\mathrm{B}_{\mathrm{o}}\right)$ and consequently also of the orientation of a given molecular structures. It is most convenient to orient the bilayer normal parallel to $\mathrm{B}_{\mathrm{o}}$ as in this case the lateral and rotational diffusion of membrane-associated peptides and proteins has no effect on the relative alignment with respect to $B_{o}$, but other sample alignments are also advantageous, for example if the peptide dynamics are studied, as will be discussed in the course of this paper.

The underlying concept of using oriented solid-state NMR spectroscopy shall be illustrated on PGLa, a member of the magainin family of antimicrobial peptides, first found in Xenopus laevis frogs (Table 1). The sequence of the peptide has been determined (Zasloff, 1987) and can be prepared, for example, by solid-hase peptide synthesis (cf. below). During synthesis a ${ }^{15} \mathrm{~N}$ label was incorporated at the $\mathrm{Ala}^{14}$ position the peptide reconstituted into oriented membranes and the solid-state NMR spectrum recorded (Fig. 1). Due to some unique properties of the ${ }^{15} \mathrm{~N}$ chemical shift tensor of the amide bond the ${ }^{15} \mathrm{~N}$ chemical shift of this site allows one a direct read out of the approximate helical tilt angle (Bechinger and Sizun, 2003). The chemical shift $<100 \mathrm{ppm}$ (here $90 \mathrm{ppm}$ ) indicates that the labelled ${ }^{15} \mathrm{~N}-{ }^{1} \mathrm{H}$ vector, and therefore the long axis of this helical peptide, is aligned approximately parallel to the membrane surface, whereas transmembrane orientations exhibit resonances in the $200 \mathrm{ppm}$ region. This is confirmed by a more quantitative analysis where the alignment of the peptide is systematically tested by screening for all possible combinations of tilt and azimuthal angles. The topological analyis shown in Figure $2 \mathrm{~A}$ indicates that the ${ }^{15} \mathrm{~N}$ chemical shift measurements restrict the tilt angles to within $35^{\circ}$ from perfectly in planar alignment, whereas all rotational pitch angles remain possible. By taking into account also the ${ }^{2} \mathrm{H}$ quadrupolar splitting of the ${ }^{2} \mathrm{H}_{3}-\mathrm{Ala}^{10}$ site the very different orientation-dependence of this interaction becomes apparent by the ensemble of angular pairs which agrees with this measurement (Fig. 2A, dotted lines). Due to the highly complementary nature of the two measurements only seven intersections remain thereby restricting the possible tilt and the rotational pitch angle of the membrane-inserted helix domains.

Additional solid-state NMR measurements or energetic considerations can further narrow down the set to a unique solution, an approach that has been demonstrated, for example, on model sequences (Aisenbrey and Bechinger, 2004b), alamethicin (Bertelsen et 
al., 2007), viral protein domains (Aisenbrey et al., 2006c), phospholamban (Traaseth et al., 2009), PGLa (Strandberg et al., 2006), phylloseptins (Bechinger et al., 2011) or the two chains of the heterodimer distinctin (Resende et al., 2009; Verardi et al., 2011). These experiments indicate that by measuring three or more experimental restraints it is possible to unambiguously determine the membrane topology of polypeptides experimentally (Bertelsen et al., 2007; Salnikov et al., 2010a) and, to push even further, to perform a detailed structural analysis of membrane-associated polypeptides (Cross, 1997). Notably however, a full structural analysis requires that for each residue a multitude of angular restraints become available. This can be achieved by preparing and analysing many different samples each labelled differently (Bechinger et al., 1993; Cross, 1997), or by NMR spectroscopic approaches that allow for the assignment and structural analyis of uniformly labelled polypeptides (Marassi et al., 2000).

\section{Preparation of peptides and their reconstitution into oriented bilayers}

Clearly, isotopic labelling is important for these investigations and the resolution and signal assignment are directly linked to the several steps involved in sample preparation. In the following the synthesis of polypeptides and the preparation of oriented membranes shall be discussed shortly, when at the same time additional details can be found in the original literature and step-by-step protocols have been published (e.g. (Aisenbrey et al., 2010; Bechinger et al., 2010)).

In the past solid-phase peptide synthesis has been the method of choice for most studies on antimicrobial peptides as the technique is ideally suited to prepare several tens or even hundreds of milligrams of peptides and in many cases the preparation of the antimicrobial sequences of 20-30 residues in length can be performed at good yields and quality using the standard protocols of automatic peptide synthesizers. Furthermore, the approach allows one to introduce isotopic labels, many of them commercially available, at specific sites, which are prerequisites for the described solid-state NMR spectroscopic investigations.

More recently, an alternative approach has been used which consists in preparing polypeptides by bacterial over expression and subsequent purification. This approach can be convenient when uniform or selective (one type of amino acid) labelling schemes are required. However, many membrane-active peptides and proteins are toxic to bacterial cells and need to be prepared either as fusion constructs with neutralizing proteins, or they have to be over- 
expressed in such a manner to form non toxic inclusion bodies (cf. e.g. (Park et al., 2009; Vidovic, 2010) and references cited therein).

In a next step the peptides are reconstituted into membranes, which, as discussed above, for some of the solid-state NMR approaches requires the uniaxial alignment relative to the magnetic field direction. A classical approach consists in dissolving a film of peptides and lipids in a suitable organic solvent, concentrating this homogenous solution under a stream of nitrogen gas and application of the viscous mixture onto a number of small ultra-thin glass plates. In several cases, it has proven helpful for efficient rehydration and membrane alignment to include naphthalene in the organic solvent mixture and removing it later during the high vacuum drying process (Hallock et al., 2002a). The sample is left in air to allow much of the organic solvent to evaporate and thereafter exposed to high vacuum. Thereafter the membranes are equilibrated in defined humidity (usually 93\% r.h.) above the gel-to-fluid phase transition temperature. This choice of temperature is important to achieve good and reproducible results. In the next step the glass plates are stacked on top of each other and the sample is finally stabilized by Teflon tape and sealed. For more detailed protocols including illustrations the reader is referred to (Aisenbrey et al., 2010; Bechinger et al., 2010; Goldmann et al., 2007).

An alternative approach consists in reconstituting the peptides in membranes that autonomously align in the magnetic field of the NMR spectrometer. These are obtained by mixing long and short chain phospholipids (or detergents) that spontaneously self-organize into bicellar structures (Gayen and Mukhopadhyay, 2008; Lee et al., 2008; Vold et al., 1997). By carefully selecting the composition and environmental conditions bicelles align in the magnetic field of the NMR spectrometer, an effect that is routinely used in solution NMR spectroscopy to measure residual dipolar couplings and/or chemical shift anisotropies (Brunner, 2001; Ottiger and Bax, 1998; Prestegard, 1998). Depending on the detailed composition of the lipid mixtures the bicelles align with the membrane normal either perpendicular or parallel to the magnetic field, where the first is the more common arrangement (Loudet et al., 2007; Triba et al., 2006). Bicellar systems have also been used to align membrane-associated peptides for solid-state NMR structural investigations (De Angelis et al., 2011). Although the approach works relatively well for membrane-inserted antimicrobial polypeptides it offers less flexibility when applied to amphipathic sequences. Although the high lipid concentrations of the bicellar media ensure that the large majority of peptides is associated with the lipids (assuming $\mathrm{K} \geq 1000 \mathrm{M}^{-1}$; (Wieprecht et al., 1999)) problems may arise from dynamic exchange of amphipathic sequences between the membrane 
and the water phase, between the flat central areas and the surrounding rims, or even the preferential alignment with the highly curved rim from by the short-chain lipids/detergents. Furthermore, in addition to the diffusion along the bilayer surface the bilayer itself wobbles and tumbles around the membrane normal. All of these cause efficient averaging of the anisotropic NMR interactions, and furthermore such motions hamper the application of signal enhancement techniques using cross polarisation.

\section{Solid-state NMR investigations of the membrane topology of host defence peptides}

Magainins are among the linear cationic antimicrobial peptides probably the ones that have been investigated most intensely by solid-state NMR spectroscopy or other biophysical techniques (e.g. (Bechinger et al., 1998; Dathe et al., 2001; Ludtke et al., 1995; Matsuzaki et al., 1994; Wieprecht et al., 2000)). In particular solid-state NMR spectroscopy provided the first indications for the alignment of linear cationic antimicrobial peptides parallel to the membrane surface thereby contrasting the models most common at the time which postulated the formation of transmembrane helical bundles (Bechinger et al., 1991; Bechinger et al., 1990). Furthermore, by investigating eight ${ }^{15} \mathrm{~N}$ labelled sites of magainin 2 using protondecoupled ${ }^{15} \mathrm{~N}$ solid-state NMR spectroscopy, four of them following each other in the sequence, it was possible to demonstrate that among all low-energy structures only a righthanded $\alpha$-helix oriented parallel with the membrane surface agrees with the experimental data (Bechinger et al., 1993).

With the availability of uniformly ${ }^{15} \mathrm{~N}$ labelled sequences it is possible to measure an increased number of correlations between ${ }^{15} \mathrm{~N}$ chemical shift and the ${ }^{1} \mathrm{H}_{-}{ }^{15} \mathrm{~N}$ dipolar coupling in a two-dimensional solid-state NMR experiment (Ramamoorthy et al., 2004). However, it should be noted that the assignment of resonances from such spectra is far from routine (Aisenbrey et al., 2009) and is often based on the assumption of a helical secondary structure that is then confirmed and refined by the solid-state NMR measurements (Marassi et al., 2000). Although the angular restraints obtained from of the ${ }^{1} \mathrm{H}_{-}{ }^{15} \mathrm{~N}$ dipolar interaction and the ${ }^{15} \mathrm{~N}$ chemical shift tensor result in closely related angular restraints the availability of many of them suffices to test the secondary structure (Kim and Cross, 2004; Salnikov et al., 2009b; Tang et al., 2006) and can also reveal the presence of kinks or gaps in helices (Traaseth et al., 2006). Furthermore this type of two-dimensional correlation spectroscopy reveals the peptide's tilt angle relative to the membrane normal (Kim and Cross, 2004). For magainin 2 the cross correlation peaks were assigned by combining uniform and selective (one or a few amino acid 
types) labelling schemes which allowed insight into the tilt and rotational pitch angle when this antimicrobial peptide is associated with oriented bilayers (Marassi et al., 2000).

Using a variety of techniques the surface alignment of magainin 2 was confirmed in membranes of different lipid composition (recently reviewed in (Bechinger, 2011)). Notably, this in-plane topology agrees well with the amphipathic three-dimensional structure and highly cationic character of these sequences (reviewed e.g. in (Bechinger, 1999; Zasloff, 2002)). In the mean time similar membrane topologies have been observed for PGLa (Bechinger et al., 1998; Tremouilhac et al., 2006), a number of magainin analogues (Mason et al., 2009; Ramamoorthy et al., 2006; Strandberg et al., 2008) and other cationic polypeptide sequences (many shown in Table 1) such as dermaseptin (Pouny et al., 1992), piscidin (De Angelis et al., 2011), pardaxin (Hallock et al., 2002b; Ramamoorthy et al., 2010), maximim-4 (Heinzmann et al., 2011), designed pore-forming cytotoxic or antimicrobial peptides (Mason et al., 2009; Ouellet et al., 2007; Ouellet et al., 2010), several peptides isolated from Australian tree frogs (Balla et al., 2004), dermadistinctin K (Verly et al., 2009), LL-37 (Henzler-Wildman et al., 2004) or the heterodimer distinctin (Resende et al., 2009). In contrast to these highly charged amphipathic sequences a range of different topologies has been observed for other less polar membrane-associated peptides of similar size (Aisenbrey et al., 2007; Bechinger, 2001; Kouzayha et al., 2009; Porcelli et al., 2004; Salnikov et al., 2010a; Sudheendra and Bechinger, 2005). Furthermore, $\beta$-hairpin structures that are stabilized by cystine bridges exhibit topological transitions from in-planar to tilted and transmembrane configurations that are dependent on the membrane lipid composition, the peptide-to-lipid ratio and peptide-peptide interactions Hong, $2011 \# 11095\}$. The oriented ${ }^{15} \mathrm{~N}$ spectra are less easy to analyse than for helical sequences due to a less homogenous alignment of the individual $\beta$-hairpins relative to the membrane normal (Salnikov et al., 2011; Tang et al., 2006). Among the few sequences analysed with solid-state NMR spectroscopy are protegrin 1, tachyplesin, human $\alpha$-defensins and arenicins (Hong and Su, 2011; Salnikov et al., 2011) (cf. Table 1).

In order to gain additional insight into the mechanisms of pore formation and the antimicrobial activities of amphipathic peptides, model sequences were designed in which the core structure consists of alanine and leucine residues but where a polar face is created by the insertion of four histidines (LAH4 peptides; Table 1). Two lysines at each terminus improve handling of these sequences and assure improved solubility in aqueous environments. The amino acid compositions results in a high propensity of the peptides to adopt $\alpha$-helical 
conformations in membrane environments (Georgescu and Bechinger, 2010; Vogt and Bechinger, 1999), and as the histidines exhibit pK values around 5.5, the hydrophobic moment and the detailed structure of these sequences is strongly affected by the $\mathrm{pH}$ of the environment (Georgescu and Bechinger, 2010). As a consequence proton-decoupled ${ }^{15} \mathrm{~N}$ solid-state NMR and ATR-FTR spectroscopies indicate that the helices orient parallel to the bilayer surface at $\mathrm{pH}<6$ when the histidines are cationic, but occurs in a transmembrane alignment at neutral pH (Bechinger, 1996; Bechinger et al., 1999b).

When the activities of members of the LAH4 family of peptides were tested for poreformation (Marquette et al., 2008) and antimicrobial action they show potent activities in particular at acidic $\mathrm{pH}$ thereby indicating that a well-defined transmembrane channel structure is not required (Vogt and Bechinger, 1999). This data has helped to design improved peptide sequences that exhibit potent antimicrobial action against a number of clinical isolates (Mason et al., 2009).

Whereas the average topology of some membrane-associated polypeptides, and of host defence peptides in particular, has been determined with high accuracy in terms of tilt and rotational pitch angles using oriented solid-state NMR spectroscopy a more detailed analysis of the NMR line shapes has allowed one to extract information about the variation of the peptide orientations in a residue-specific manner (Aisenbrey and Bechinger, 2004b; Aisenbrey et al., 2006c; Ramamoorthy et al., 2009; Resende et al., 2009; Traaseth et al., 2006). By comparing experimental and simulated spectra information about conformational equilibria as well as local or global motions of the polypeptide are obtained, features which can be essential to understand the interactions and functioning of these sequences in liquid disordered membranes (cf. Table 2). Furthermore, such features have been analysed in terms of heterogeneity of the sample, which is an indicator for the co-existence of mono- and oligomers, for conformational exchange and/or sample mosaicity (Traaseth et al., 2006).

In particular the deuterium line shape of the alanyl-methyl group is a very sensitive indicator of the mosaic spread of the alignment vector where, depending on the absolute angle, reorientation of the $\mathrm{C} \alpha-\mathrm{C} \beta^{2} \mathrm{H}_{3}$ group by as little as $1^{\circ}$ become obvious by significant alterations in the quadrupolar splitting (Bechinger et al., 2011). This feature revealed small topological alterations of a model peptide when the ${ }^{2} \mathrm{H}$ spectra in DPPC or DOPC are compared to each other (Aisenbrey and Bechinger, 2004b). Whereas the ${ }^{2} \mathrm{H}$ NMR line shapes of some model sequences are indicative of well-defined alignments $\left( \pm 1^{\circ}\right)$ (Aisenbrey and Bechinger, 2004b), the heterodimeric peptide distinctin exhibits a mosaicity of $\pm 2^{\circ}$ for its second chain, which tightly associates with the membrane, but much higher flexibility for 
chain 1 (Resende et al., 2009). Visual inspection of the deuterium spectra of 2 mole\% PGLa in DMPC and of WALP23 in DMPC are suggestive of similarly well-defined alignments (Strandberg et al., 2004; Strandberg et al., 2006), whereas the helical domain of the viral protein ICP47 exhibits a $10^{\circ}$ orientational distribution in POPC bilayers (Aisenbrey et al., 2006c).

In this context it is also notable that the line shapes obtained from peptides reconstituted into non-oriented membranes can also yield tilt angle information provided the peptides undergo fast rotational diffusion around the membrane normal (Bechinger and Sizun, 2003; Cady et al., 2007; Prongidi-Fix et al., 2007) (cf. Table 2 for typical correlations times). Whereas in the past the line distortions that were caused by cross-polarisation hampered the quantitative analysis of such spectra a novel solid-state NMR experiment efficiently removes such artefacts and provides close-to-perfect line shapes that are straightforward to analyse (Hirschinger et al., 2011).

\section{Proton-decoupled ${ }^{31} \mathrm{P}$ solid-state NMR approaches to monitor the lipid macroscopic phase properties, structure and dynamics}

Having firmly established that the in-planar alignment of the peptide is an (or the most) active configuration in antimicrobial and pore-forming assays the question remains how this can be explained on a molecular level? In order to answer this question investigations of the lipid building blocks in mixed membranes have been performed and such studies reveal interesting insight into the mechanism of action of the peptides. Indeed, ${ }^{31} \mathrm{P}$ solid-state NMR spectroscopy has been developed to monitor the phase transitions of membranes (Cullis and De Kruijff, 1979) and more recently also of whole organelles (Sani et al., 2009). Whereas bilayer and hexagonal phases exhibit characteristic ${ }^{31} \mathrm{P}$ powder pattern line shapes, isotropic signal intensities are usually assigned to small fast tumbling structures or to membrane domains exhibiting high curvature, including lipid cubic phases (Cullis and De Kruijff, 1979). A more detailed line shape analysis has been performed through spectral simulations indicating that the ${ }^{31} \mathrm{P}$ spectra are rich in information on the size, polydispersity and (multi-) lamellarity of vesicles (Douliez et al., 1994). Notably the occurrence of isotropic lines in ${ }^{2} \mathrm{H}$ and ${ }^{31} \mathrm{P}$ solid-state NMR spectra does not necessarily have to be associated with the presence of small fast tumbling liposomes (typically < $200 \mathrm{~nm}$; (Traikia et al., 2000)) but can also occur due to pronounced polydispersity and the resulting small structures that are hidden inside larger vesicles (Douliez et al., 1994). Both ${ }^{31} \mathrm{P}$ and ${ }^{2} \mathrm{H}$ solid-state NMR spectroscopies 
also allow one to characterize the magnet-induced deformations and alignment of vesicles (Picard et al., 1999; Pott and Dufourc, 1995) or the magnetic alignment of bicelles (Sanders II et al., 1994; Triba et al., 2005). Notably, using a quantitative analysis of the ${ }^{31} \mathrm{P}$ NMR spectra it has been possible to refine our view on the distribution of long- and short-chain lipids and the temperature-dependent morphology of the bicelles (Triba et al., 2005; Triba et al., 2006). Another interesting application is in the use of paramagnetic shift reagents to quantify the number of lipids exposed on the outside monolayer (e.g. (Barsukov et al., 1980; Moreau et al., 2001)) although to our knowledge this has not yet been applied to the investigation of antimicrobial peptides.

Interestingly, using ${ }^{31} \mathrm{P}$ solid-state NMR in combination with electron microscopy it has been observed that, depending on the detailed lipid and buffer conditions, the membrane morphology changes when the lipid suspensions undergo a number of freeze/thaw cycles (Traikia et al., 2000). Whereas 'small vesicles' form (as defined by their isotropic ${ }^{31} \mathrm{P}$ NMR signals) in the presence of salt and when the lipids are in the fluid state at temperatures where the water phase freezes, fusion of sonicated vesicles can also occur under different conditions. Notably, we have ourselves observed that the tendency for isotropic ${ }^{31} \mathrm{P}$ NMR intensities augments when liquid nitrogen and hot water baths are used rather than slow-freeze cycles (such as freezing in dry ice bath or in the freezer / thawing at room temperature). Therefore, when the effects of peptides or other additives are studied it is important to run in parallel controls of pure lipid vesicles throughout the full preparation cycle.

Using proton-decoupled ${ }^{31} \mathrm{P}$ solid-state NMR the interactions of peptides with phospholipid membranes have early on been investigated. As the ${ }^{31} \mathrm{P}$ nucleus occurs at $100 \%$ natural abundance labelling is not required during sample preparation. In particular the interactions of the bee venom peptide melittin and its effect on the macroscopic phase preferences of a wide variety of lipids and lipid mixtures has early on been investigated (reviewed in (Bechinger, 1997), as well as more recent investigations (Pott et al., 2001; Pott et al., 1998)).

When the interactions of magainin 2 with phosphatidylcholine membranes have been studied isotropic signal intensities have been found to co-exists with bilayer structures, and at higher peptide-to-lipid ratios the membranes orient in the magnetic field, a behaviour that is similar to when detergent-phospholipid mixtures are prepared to form bicelles (Bechinger, 2005; Bechinger and Lohner, 2006). Notably, subtle difference have been observed if the peptides were added after the formation of vesicles or when co-dissolved with the lipid in organic solvent first, an observation that may be related to the tendency of some amphipathic 
peptides to form small aggregates or metastable supramolecular assemblies with the lipids (Bechinger, 2001; Bello et al., 1982; Marquette et al., 2008; Pott et al., 1998). A comprehensive ${ }^{31} \mathrm{P}$ solid-state NMR investigation has also been published for pardaxin, a membrane-lytic peptide from the fish Pardachirus marmoratus (Table 1). Bilayer disruption was indeed observed for POPC membranes where the peptide aligns parallel to the membrane surface and this effect is attenuated in the presence of negatively charged lipids or cholesterol (Hallock et al., 2002b).

Furthermore, ${ }^{31} \mathrm{P}$ NMR spectra of the oriented samples reveal interesting details about the modulations of the phospholipid packing when amphipathic helices insert into the membrane interface. Whereas the homogenous lipid alignment of a perfectly oriented phospholipid bilayer results in a single ${ }^{31} \mathrm{P}$ resonance (Fig. 3A) additional intensities at lower chemical shift positions become apparent when a peptide induces distortion in the alignment of the phospholipids, or if a sample is less homogenous for example due to imperfect preparations or due to defect structures (Fig. 3B,C). Figure 3B shows that simple storage at $-20{ }^{\circ} \mathrm{C}$ for extended time periods (concomitant with dehydration) can cause such imperfections much of which are reversible upon re-equilibration at high humidity (93\% r.h., not shown). Interestingly, such additional intensities reaching into the $-15 \mathrm{ppm}$ region for phosphatidylcholines (Fig. 3C) reoccur consistently for in-planar peptides but not TM sequences even though the analogous protocols are applied (Aisenbrey et al., 2010). Therefore, it is believed that these signal intensities are related to the mechanisms of action of the peptide and do not merely reflect 'sample artefacts' or 'bad alignment'.

When mixed membranes of PC and PG are aligned onto the glass plates the two phospholipids exhibit barely resolved chemical shifts at the zero-degree intensity (Fig. 3D), the resolution being enhanced when the sample is tilted by 90 degrees (Fig. 3E). This can be explained by a significant difference in chemical shift anisotropy ( $5 \mathrm{ppm}$ ) concomitant with a $1.1 \mathrm{ppm}$ displacement of the isotropic chemical shifts of the two lipids (Fernandez et al., 2011; Mason et al., 2006). As a consequence in a non-oriented sample the 90degree intensities are well-resolved whereas the 0-degree region barely reveals the twocomponent nature of the spectrum (Fig. 3F).

As membrane thinning has been detected due to the presence of cationic amphipathic peptides using diffraction techniques (Ludtke et al., 1995) or when investigating peptidedeuterated phospholipid mixtures by ${ }^{2} \mathrm{H}$ solid-state NMR (e.g. Fig. 5 and (Salnikov et al., 2010a)) Sungsool Wi and co-workers have simulated how such thinning would effect the oriented ${ }^{31} \mathrm{P}$ solid-state NMR spectra (Kim et al., 2009; Wi and Kim, 2008). The underlying 
model is shown in Figure 4A, where the peptide causes an indentation of the membrane of depth $d$ and radius $a$. As a consequence the lipids change their alignment when diffusing laterally and a distribution of lipid orientations results. Two simulations are illustrated in Figure 4B, namely slow diffusion when compared to the NMR time scale in which case a broad ${ }^{31} \mathrm{P}$ line shape is observed reflecting the probability of finding the underlying molecular alignments within the sample (Fig. 4B, center), or fast diffusion in which case an average of the above distribution function is obtained (Fig. 4B, bottom). Indeed reduced chemical shift anisotropies concomitant with a shift of the zero-degree resonance has been observed when antimicrobial peptides, including PGLa, interact with phospholipid bilayers (e.g. Fig. 3C). The 0.5 ppm shift, observed in the presence of PGLa (compare Figs. 3A, C) corresponds to an a/d value of $\sim 0.1$ when the model presented in Figs $4 \mathrm{~A}, \mathrm{~B}$ is taken in consideration, although it should be noted that such small differences are barely significant and could probably also arise from changes in salt content, $\mathrm{pH}$, hydration etc. (e.g. (Scherer and Seelig, 1989)).

Furthermore, the ${ }^{31} \mathrm{P}$ NMR spectra of lipid orientational distributions such as they have been suggested to occur in torroidal pores have been simulated as a function of phospholipid lateral diffusion (Kim et al., 2009; Wi and Kim, 2008). The geometry of such a pore is shown in Fig. 4C where $d$ is the elliptic semiminor of the ring torus, $b$ the monolayer thickness and $a$ the pore diameter. The resulting spectra, when assuming $a=b$, are shown as a function of the lateral diffusion constant and the ratios $d / b=0.5$ (Fig. 4D), 1 (Fig. 4E) or 1.4 (Fig. F). In the case of slow diffusion the molecules appear 'fixed' at given orientations relative to the magnetic field direction / glass plate normal and the spectra therefore show contributions from all the alignments (Fig. 4D-F, bottom row). Notably for the pore itself line shapes closely similar to powder patterns are obtained under certain conditions (Fig. 4D) although it should be taken into considerations that in a real sample the flat parts of the membrane will make additional 'oriented' contributions at the zero-degree intensity (i.e. in the region 25 - 30 ppm for phosphatidylcholines). When the lateral diffusion rates increase the distribution functions are successively averaged and finally, at rates that are commonly observed for liquid crystalline membranes (Table 2), a single resonance intensity results (top row of Figs. 4 D-F).

Indeed resonance intensities reaching into the 90-degree region are consistently observed when the ${ }^{31} \mathrm{P}$ solid-state NMR spectra of oriented membranes are recorded in the presence of amphipathic peptides (e.g. (Hallock et al., 2003; Kim et al., 2009; Verly et al., 2009)). Therefore, it has been suggested that the broad distribution function simulated under conditions of slow diffusion are indicative of torroidal pores, but it should be noted that these 
diffusion rates are at least 3-4 orders in magnitude slower than those usually observed in liquid-disorder membranes (Table 2). Therefore, although it is quite attractive to associate these intensities with 'torroidal pores' questions about this interpretation remain and it remains possible that other contributions can explain the intensities that reach into the -15 ppm range. These could arise, among other possibilities, from lipid domains at different alignments that are spatially separated, or from powder pattern line shapes which may occur from folding-back of the bilayers or from the proximity of particles or aggregates.

Furthermore, undulations of the membranes have been described and these occur at slow time scales (Table 2) and may contribute to line broadening (Dufourc et al., 1992). Although such motions have been suggested to be reduced when supported bilayers are investigated (Glaubitz and Watts, 1998) they may need to be considered to understand all the details of the oriented ${ }^{31} \mathrm{P}$ solid-state NMR spectra. Notably, when two-dimensional ${ }^{31} \mathrm{P}$ exchange spectra were analysed early on the experimental cross peak intensities in the $\mathrm{P}_{\beta}$, phase were attributed to lateral diffusion over curved 'ripple structures' or within/along disordered defect structures (Fenske and Jarrell, 1991). It is also noteworthy that the small signal intensity observed at about 20 ppm upon aging of the sample (Fig 3C) could equally well be indicative of lipids undergoing fast diffusion through a pore structure (Fig. 4D-F, top row). Although it is usually assumed that such signal arise from lipid degradation, a hypothesis that is favoured by the accelerated appearance at low $\mathrm{pH}$ when compared to $\mathrm{pH}$ 6.5, it should be kept in mind that such artefacts would superimpose and hide resonances from pore structures as shown in Fig 4C. This would be the case if such structures need time to form, a possibility that remains an option in view of the observation of metastable intermediates within peptide-lipid supramolecular aggregates (Bechinger, 2001; Bello et al., 1982; Marquette et al., 2008; Pott et al., 1998).

\section{${ }^{2} \mathrm{H}$ solid-state NMR spectroscopy reveals lipid order and packing}

Whereas the macroscopic phase changes and the occurrence of torroidal pore structures is also reflected in the ${ }^{2} \mathrm{H}$ solid-state NMR spectra of deuterated phospholipids (Kim et al., 2009; Wi and Kim, 2008), and has been used to establish lipid phase diagrams in complex mixtures (Aussenac et al., 2003; Juhasz et al., 2009; Loudet et al., 2007), here we will focus on reviewing how this approach has been used to study membrane thinning (Ludtke et al., 1995) as well as the membrane packing in a segment-specific manner (Bechinger et al., 1992; Kim et al., 2009; Salnikov et al., 2009c; Vermeer et al., 2007). In order to monitor changes in 
the lipid packing quadrupolar solid-state NMR spectra are measured from phospholipids encompassing deuterated fatty acyl chains. From such non-oriented samples quadrupolar splittings ( $\Delta v$, cf $\square \square$ Fig $\square \square 5 \mathrm{~A}$ ) of up to $120 \mathrm{kHz}$ were observed at low temperatures.

However, at room temperature a number of motions, including trans-gauche isomerizations, wobbling of the molecules or rotation around bilayer normal cause considerable averaging (Griffin, 1981; Marsan et al., 1999; Seelig, 1977) and $\Delta v$ values $<40 \mathrm{kHz}$ are typically observed (Fig. 5A; note that isotropic realignment would completely average $\Delta v \rightarrow 0$ ). The structure of the lipid fatty acyl chains are therefore best described by segment specific order parameters which are directly calculated from the $\mathrm{C}-{ }^{2} \mathrm{H}_{2}$ deuterium quadrupole splittings according to $\Delta v^{i}=\frac{3}{2}\left(\frac{e^{2} q Q}{h}\right)\left(\frac{3 \cos ^{2} \Theta-1}{2}\right) S_{C D}^{i}$ (Seelig, 1977). By taking this approach the measured deuterium quadrupole splitting is compared to the static maximal splitting. For practical reasons the quadrupolar splittings are often determined from the distance between the intensity maxima in a non-oriented sample (Fig. 5A), which correspond to the $\Theta=90^{\circ}$ alignment (included in $S_{\text {bilayer, }}$ cf. below). With a quadrupolar coupling constant $\left(\frac{e^{2} q Q}{h}\right)$ of 167 $\mathrm{kHz}$, or $175 \mathrm{kHz}$ in the context of a double bond (Marsan et al., 1999; Seelig, 1977), the maximal splitting is $\sim 125 \mathrm{kHz}$ for a static $\mathrm{C}^{2}{ }^{2} \mathrm{H}$ segment and the deuterium order parameter is a measure of the motional anisotropy of the selected $\mathrm{C}-{ }^{2} \mathrm{H}$ bond and defined as $S_{C D}^{i}=\frac{1}{2}\left(3 \overline{\cos }^{2} \beta_{i}-1\right)$, where $\beta_{l}$ is the instantaneous angle between the $\mathrm{C}-{ }^{2} \mathrm{H}$ vector and the bilayer normal and the bar indicates the time average (Seelig and Seelig, 1980; Vermeer et al., 2007). When different motional regimes contribute to averaging these can be considered in a simple step-by-step manner by calculating each of the resulting order parameters separately $\Delta v^{i}=\frac{3}{2}\left(\frac{e^{2} q Q}{h}\right) S_{\text {bilayer }} S_{m o l} S_{\text {loc }}^{i}\left(\frac{3 \cos ^{2} \beta_{i}-1}{2}\right)$. Here $S_{\text {bilayer }}$ represents the degree of order and alignment of the bilayer normal (e.g. wobbling motions, differently aligned membranes), $\mathrm{S}_{\text {mol }}$ is the molecular order, $\mathrm{S}_{\text {loc }}$ the local order (e.g. motions and alignment at the level of a particular bond), and $\beta_{1}$ the angle between the $\mathrm{C}^{2} \mathrm{H}$ bond and the axis of motion (e.g. membrane normal) (Marsan et al., 1999; Seelig, 1977). Thus rotations around the bilayer normal causes a reduction of the quadrupolar splitting of the fatty acyl chain $\mathrm{C}-{ }^{2} \mathrm{H}$ (assuming $\theta \mathrm{mol}=90^{\circ}$ ) by $-1 / 2$, or free rotation of a methyl group reduced its quadrupolar splitting by $S_{\text {loc }}=-1 / 3$ by taking into account a tetrahedral angle of $109.4^{\circ}$ (Batchelder et al., 1983; Seelig, 1977).

Figure 5A shows the ${ }^{2} \mathrm{H}$ solid-state NMR spectrum of POPC multilamellar vesicles labelled with ${ }^{2} \mathrm{H}$ all along the palmitoyl chain in the absence and in the presence of 2 mole $\%$ 
PGLa. Each labelled position results in a characteristic powder pattern line shape characterized by a quadrupolar splitting between its two maximal intensities (Fig. 5). Alternatively the ${ }^{13} \mathrm{C}-{ }^{1} \mathrm{H}$ couplings have been used for such an analysis (Douliez et al., 1996)

As shown above the quadrupolar splitting is a measure of the average alignment of the $\mathrm{C}-{ }^{2} \mathrm{H}$ vector and in the case of the fatty acyl chains predominantly reflect the positiondependent dynamic averaging. Within the phospholipid bilayer the motions are most restricted close to the glycerol backbone and continuously augment towards the membrane interior. Therefore the quadrupolar splittings decreases along the palmitoyl chain (Seelig and Seelig, 1980). This is illustrated in Fig 5B where PGLa has been reconstituted into POPC-d $\mathrm{d}_{31}$ bilayers. The amphipathic peptide helix intercalates into the interface thereby increasing the space available at the level of the hydrophobic interior of the membrane. In order to fill the gap the fatty acyl chains extend below the peptide, adopt a higher ratio of gauche conformations and decrease the order parameter of individual segments (Fig. 5B). The observed changes in order parameter can be translated into a membrane thinning effect according to $\Delta d=2.54 \AA \cdot \Sigma\left(\Delta S_{C D}\right)\{$ Nagle, $1993 \# 9088\}$, which due to the presence of 2 mole\% PGLa amounts to $0.3 \AA$.

With the commercial availability of deuterated phospholipids a wide range of studies have been published investigating the order parameters in the presence of various membraneactive antimicrobial peptides and a selection from the more recent literature shall be presented. Whereas a relatively modest decrease in the POPC order parameter has also been observed when magainin 2 or aurein 3.3 (Table 1) is mixed with pure lipid or in the presence of cholesterol this effect is much more pronounced when POPC-d31/POPG 3:1 mole/mole membranes are investigated and has been simulated with the torroidal pore model (Bechinger et al., 1992; Kim et al., 2009). Segment specific alterations of DMPC-d54 or DMPC-d 54 / DMPG membranes have been monitored in the presence of falladixin 4.1a (Table 1)

(Sherman et al., 2009).

A decrease in the POPC order parameter has also been observed for pardaxin when the peptide is oriented parallel to the membrane surface (Porcelli et al., 2004). Consistent with this view is the correlation of such decreased order parameters with interfacial localisations but not with transmembrane peptide alignments (Salnikov et al., 2009c). In this manner the amphipathic peptide acts analogous to a detergent which has conceptually been described as an inverted cone and which increases the curvature strain of the membrane (Bechinger, 2009). PG membranes with fatty acyl chains of 14 and 16 but not $18 \mathrm{C}$-atoms has been observed (Pabst et al., 2008) illustrating the difficulties of deducing a topological model from the 
measurements of such indirect effects on the lipid fatty acyl chains without other information such as e.g. from ${ }^{15} \mathrm{~N}$ solid-state NMR spectroscopy (cf. above). Notably, the influence of the peptide can be many fold and increased order can occur due to motional restraints imposed by a peptide deeply inserted into the membrane (e.g. TM oriented), condensation of the lipids due to the superficial association of polymers with the lipid membrane, or the specific interactions of the peptide with only selected lipid components of the membrane, which as a consequence changes the lipid composition next to the labelled fatty acyl chain. Indeed by selectively labelling one lipid over the other it has been possible to monitor preferential interactions of cationic antimicrobial peptides with the anionic lipids in PC/PS or PC/PG mixtures (Bourbigot et al., 2009; Jean-Francois et al., 2009; Mason et al., 2006; Sherman et al., 2009).

The interactions of the arginine-rich antimicrobial peptide cateslytin (Table 1) were investigated using ${ }^{2} \mathrm{H}$ solid-state NMR of membranes where some of the components were labelled with deuterium (Jean-Francois et al., 2009). The studies show a selectively interaction with the anionic component of the DMPC/DMPG lipid bilayer. In the presence of sterols an efficient phase separation into fluid/thinner membranes and rigid/thicker membranes that are not bound to the peptide with the concomitant creation of boundary defects was observed. In this context it was suggested that when compared to cholesterol-rich membranes the more fluid ergosterol containing bilayers of fungi can explain the selective antimicrobial action of the peptide. The effects of sterols on the macroscopic phase properties of membranes were recently reviewed (Dufourc, 2008). Interestingly a short helical segment is stabilized in membrane environment in the extended catestatin peptide (Table 1) thereby considerably changing its membrane interaction properties (Sugewara et al., 2010).

Pore-forming model peptides of a repetitive structure of five leucines and two crownether-phenylalanines (CE-model peptide; Table 1) have been investigated using solid-state NMR. These peptides show a surface association and their effects on the lipid order parameter of DMPC and DPPC were studied by ${ }^{2} \mathrm{H}$ solid-state NMR (Ouellet et al., 2007; Ouellet et al., 2010). In the presence of the 21-mer a slight increase in the order parameter of fatty-acyl chain deuterated bicelles was observed for the plateau region (i.e. the sites closest to the glycerol backbone) whereas the changes were less pronounced in the membrane interior (Ouellet et al., 2010).

In a related manner the antimicrobial peptides aurein 1.2, citropin 1.1, maculatin 1.1 and caerin 1.1 (Table 1) exhibited an augmentation of the DMPC order parameter when investigated in mixtures with DMPG but had virtually no or very little effect (citropin 1.1) 
when investigated in pure DMPC (Gehman et al., 2008; Kim et al., 2009). Interestingly an antibacterial hexamer LfB6 from the lactoferin sequence (Table 1) which has been Nacetylated to improve biological activities exhibits hardly any effect on the order parameters of POPE/POPG 3:1 membranes but causes a disordering of POPC membranes (Romo et al., 2011). The NMR measurements were paralleled by MD simulations, which show an interfacial localisation of the peptide and a deep penetration of the hexyl chain.

Using ${ }^{2} \mathrm{H}$ solid-state NMR spectroscopy order parameters have also been tested on intact sperm cell and nuclear envelope precursor membranes (Gamier-Lhomme et al., 2007) as well as models thereof (Zhendre et al., 2011) or of deuterated cholesterol in human erythrocyte membranes (Kelusky et al., 1983).

\section{Phase diagrams to describe the supramolecular assemblies formed by antimicrobial peptide-lipid mixtures}

A large number of cationic peptides have been found to form amphipathic structures in membrane environments that orient along the membrane surface within the interface. A review of the membrane-structures of a number of antimicrobial sequences seems to indicate that this is the key requirement for the activity of these peptides (Zasloff, 2002). The peptidelipid interactions thereby resemble in many aspects the membrane interactions of detergents or detergent-like molecules (Bechinger et al., 1999a). The macroscopic phase preferences of lipids, lysolipids and detergents have been described by the molecular shape concept (Israelachvili et al., 1980). In an analogous manner it has been suggested that the space requirements of charged amphipathic peptides correspond to that of a cone thereby reflecting the predominant space requirements of the peptides in the head group region when at the same time the peptide cannot fill the membrane hydrophobic interior (Bechinger, 2009). Notably mixtures of magainin 2 and phosphatidylcholines exhibit similar macroscopic properties when compared to bicellar mixtures of short- and long chain lipids, namely magnetic alignment and curvature strain (Bechinger, 2005). In his context it is noteworthy that the length of the extended fatty acyl chains of DHPC and DMPC, as they are used for the formation of bicelles, are different by $9 \AA$ which matches closely the difference between the hydrophobic region of the membrane (15 $\AA$ ) and the radius of an $\alpha$-helix (5-6 $)$.

At high detergent concentration such interactions cause the disruption of the bilayer integrity as has been suggested by the 'carpet model' (Shai, 1999). However it should be kept in mind that at lower detergent/peptide concentrations the results on the membrane 
supramolecular assembly may be quite different and, depending on lipid composition, exact peptide sequence, peptide concentration, $\mathrm{pH}$, temperature, etc, may include channel formation and an even more stable lipid bilayer packing (Bechinger, 1999, 2009). It should be emphasized that membranes are soft structures and peptides and lipids can mutually adapt their conformation, topology, aggregation and ultimately their common supramolecular assembly, therefore, care should be taken to also include the lipid shape and composition when predicting the molecular arrangements of such mixtures. The strength of solid-state NMR spectroscopy is its ability to observe and characterize both the peptide and the lipid components in such a complex membrane environment. To take all of these possibilities into consideration a full description of the peptide-lipid interactions is best achieved by phase diagrams where the carpet- (Shai, 1999), torroidal pore-, wormhole- (Ludtke et al., 1996; Matsuzaki, 1998) and lysis model all occupy distinct areas (Bechinger, 1999, 2009). Notably, our improved understanding of the interactions of antimicrobial peptides with membranes, and in particular data showing that they develop action in their surface-associated state, has allowed the design of short sequences as well as peptide mimetics with potent antimicrobial activities (Kuroda and DeGrado, 2005; Makovitzki et al., 2008; Palermo and Kuroda, 2010; Patch and Barron, 2003; Porter et al., 2002; Romo et al., 2011; Rotem and Mor, 2009; Scott et al., 2008; Violette et al., 2006).

\section{Membrane topologies as a function of lipid composition}

The lipid composition of the membrane is an important variable of such phase diagrams and has allowed to explain the different interaction modes of cationic amphipathic antimicrobial molecules with bacterial and eukaryotic membranes (Bechinger, 2009). Indeed electrostatic interactions, such as they occur at the outer membrane layers of bacteria, strongly enhance the association of cationic peptides with membranes (Matsuzaki et al., 1991; Wenk and Seelig, 1998). Furthermore, the preferred macroscopic phase properties vary with membrane lipid composition and can therefore contribute to explain how antimicrobial peptides are toxic to one cell but not another (Bechinger, 2009).

A review of the biophysical data obtained on magainin 2 shows that the peptide exhibits stable in-planar membrane alignments under all conditions so far investigated (Bechinger, 2011) with only subtle changes in the presence of cholesterol (Bechinger et al., 1992). Under similar conditions alamethicin, a dodecameric sequence exhibits transmembrane orientations in DMPC and POPC albeit the exact tilt angle and secondary structure are 
somewhat dependent on lipid composition (Bak et al., 2001; North et al., 1995; Salnikov et al., 2009b). Notably, even this very hydrophobic sequence exhibits in-planar alignment when reconstituted into phosphatidylethanolamine membranes (Huang, 2000; Salnikov et al., 2010a).

Interestingly, PGLa, but not its close relative magainin 2, can adopt a variety of more membrane inserted orientations when the hydrophobic thickness of the membrane is reduced (Salnikov and Bechinger, 2011). It is even possible that in the thinnest bilayers the tilt is sufficient that the peptide spans the membrane but the data also leave open other possibilities. Furthermore the PGLa alignments in DMPC or DMPC/DMPG membranes are dependent on the peptide-to-lipid ratio and bilayer hydration. In this lipid distinct alignments have been observed, one in-planar, another one reaching into the membrane at an angle of about $30^{\circ}$, and a third at even higher insertion angles (Salnikov and Bechinger, 2011; Tremouilhac et al., 2006). Notably this concentration-dependent insertion into the membrane of PGLa has so far not been observed in 1-palmitoyl-2-oleoyl-phospholipids (e.g. POPC), a fatty acyl composition that is generally believed to better represent the hydrophobic thickness and the fatty acyl composition of natural membranes, and which form the basis for most of the magainin 2 studies (Bechinger, 2011). Indeed when PGLa is investigated in lipid extracts from natural sources the in-planar configuration is observed using ${ }^{19} \mathrm{~F}$ solid-state NMR spectroscopy (Ieronimo et al., 2010).

Interestingly, the C-terminal helix of pardaxin, a sequence rich in serines and hydrophobic residues (Table 1), thereby resembling a well-characterized leucine-serine amphipathic model peptide (LSLLSSL) 3 (Sudheendra and Bechinger, 2005), has also been shown to be in-plane in POPC, but transmembrane in DMPC (Porcelli et al., 2004). In the latter lipid the motions of the peptide augment with temperature similar to the dynamic changes also observed for the lipids, indicating that peptide-peptide interactions as they would have to occur in a barrel stave mechanism, are weak for this peptide. As a consequence cholesterol exerts a pronounced reduction of the dynamics and heterogeneity of the peptide as well as its membrane-disruptive activities (Ramamoorthy et al., 2009).

Using oriented circular dichroism spectroscopy it was shown that aurein 2.2. and 2.3 peptides (Table 1) inserted into the membrane above a certain threshold which is dependent on the PG content of DMPC/DMPG or POPC/POPG membranes (Cheng et al., 2009). A decrease in PG and an increase in bilayer thickness progressively reduced the insertion ability of the amidated peptides. Pronounced differences were also observed in the ${ }^{31} \mathrm{P}$ spectra ranging from micellisation to ${ }^{31} \mathrm{P}$ line shapes which are characteristic of torroidal and/or non- 
oriented membranes depending in a subtle manner on both the detailed lipid and amino acid composition of the aurein variant (Cheng et al., 2009). Fatty acyl chain-dependent membrane topologies have also observed for model compounds (Harzer and Bechinger, 2000) as well as some of the shorter peptaibols, such as the 15 residue zervamicin II and ampullosporin A, which exhibit in-planar alignments in POPC or DMPC but transmembrane orientations in membranes made of fatty acyl chains encompassing 12 or 10 carbon atoms (Bechinger et al., 2001; Salnikov et al., 2009b).

Finally it should be noted that subtle lipid-dependent differences in the mode of peptide-lipid interactions are not restricted to linear cationic amphipathic peptides but have also been observed for protegrin, an arginine-rich $\beta$-hairpin peptide stabilised by two cystine bonds which has been investigated in DLPC, POPE/POPG, POPC/cholesterol membranes (Hong, 2007) as well as in LPS/PE mixtures mimicking the outer membrane of Gramnegative bacteria (Su et al., 2011).

\section{Peptide dimers and synergistic action}

The membrane curvature strain imposed by the interfacial localisation of an amphipathic compound is an important driving force for the modifications of membrane topology that form the basis for the changes in electrical conductivity and pore formation. When the phase diagrams of lipid membranes have been investigated the molecular shape concept has been established where typical bilayer lipids such as PC are represented by cylinders. Furthermore, lipids with smaller head group such as PE, that exhibit a tendency for hexagonal II phases, exhibit shapes of cones, whereas detergents or lysolipids with only one fatty acyl chain look like inverted cones (Israelachvili et al., 1980). Within this concept the in-plane oriented helix predominantly occupies space in the lipid headgroup region and therefore acts analogous to an inverted cone (or a lysolipid/detergent). Extending this concept further one could hypothesize that the membrane disruptive effects are enhanced by peptides where two helices are lying side-by-side in the membrane (Bechinger, 1999) and this seems indeed to be the case for dimerized melittin (Takei et al., 1999). It is therefore interesting to note that the heterodimeric peptide distinctin, discovered in Brazilian frogs, exhibits about the same antimicrobial activities when compared to a mixture of its two non-connected chains (Brand et al., 2006). In order to rationalize these observations isotopically labelled distinctin sequences were prepared and investigated in oriented phospholipid membranes using a combination of ${ }^{15} \mathrm{~N}$ and ${ }^{2} \mathrm{H}$ solid-state NMR spectroscopies (Resende et al., 2009) as well as 
by using ${ }^{15} \mathrm{~N}$ chemical shift $-{ }^{1} \mathrm{H}_{-}{ }^{15} \mathrm{~N}$ orientational restraints (Verardi et al., 2011). Similar to the antimicrobial assays the biophysical investigations involved the covalently connected sequences as well as the two chains independently (Resende et al., 2009). First of all these studies reveal pronounced conformational changes of the dimer when associating with the membrane. Second, in the bilayer the amphipathic helix of chain 2 adopts a tilt angle of $88^{\circ}$ relative to the membrane normal and acts as a stable membrane anchor for the polypeptide. In contrast, chain 1 is more loosely bound to the membrane and the corresponding helix adopts a tilt angle of $66^{\circ}$ in the dimer and $71^{\circ}$ when chain 1 is investigated independently (Resende et al., 2009; Verardi et al., 2011). It therefore seems that the membrane interactions and functions of the dimer are governed by chain 2 whereas chain 1 helps to protect the peptide in solution from proteases through a compact dimer of dimer arrangement (Raimondo et al., 2005).

Interactions between antimicrobial sequences should be important when they mutually enhance their activities as was observed when the activities of magainin 2 and PGLa were tested in combination (Haney et al., 2009; Matsuzaki et al., 1998; Westerhoff et al., 1995). Therefore, NMR structural investigations were performed to reveal the structural basis of this synergistic enhancement. The studies show that when investigating in POPC or POPC/POPG 3:1 mole/mole model membranes both peptides remain oriented parallel to the membrane surface as is observed when they are studied individually (Salnikov and Bechinger, 2011). Therefore it remains to be elucidated how such synergies arise but it is possible that one component exhibits a strong potential to weaken the outer and /or inner membranes thereby allowing the passage of the second component, in particular if intracellular targets are also affected (Brogden, 2005).

Interestingly the tendency of PGLa to insert into thinner membranes is enhanced by magainin and the former (but not the latter) peptide undergoes a transition from in-planar to transmembrane when investigated in dimyristoylphospholipids upon addition of equimolar amounts of magainin 2 (Salnikov and Bechinger, 2011; Strandberg et al., 2009b). At least four different topologies of PGLa have been described as a function of membrane hydrophobic thickness and the one in the presence of magainin 2 is again different (Salnikov and Bechinger, 2011). Therefore the data are suggestive that direct interactions between the peptides occur, although it is interesting that the initial transmembrane insertion of PGLa can be explained by the thinning of the membranes that results from the in-plane localisation of magainin 2 (Salnikov and Bechinger, 2011). 


\section{Taking peptide motions into consideration}

Whereas solid-state NMR investigations require dedicated instrumental set-ups and relatively laborious sample preparations, this is more than compensated by the capability of the approach to furnish atomic-resolution structural information in liquid disordered bilayers. By being capable to investigate polypeptides in their native liquid disordered membrane environment solid-state NMR spectroscopy is unique in allowing for the investigation of the structure and dynamics of antimicrobial peptides in their native environment and the technique has thereby revealed much new insight into the mechanism of action of linear cationic and other antimicrobial peptides. The technique has shed light onto the structure and topology of the peptides but also the mutual interactions between peptide and lipid and the resulting membrane morphologies. At physiological temperatures the membranes are dynamic and adaptations can occur by changing the peptide conformation and topology but also by modulating the macroscopic phase properties of the membranes as a whole or locally. Whereas membrane lysis is a 'final event' during the action of these peptides pores also form transiently and stochastically (Christensen et al., 1988; Cruciani et al., 1988), activities that are probably linked to the molecular diffusion of the membrane associated peptides and lipids. It is therefore important to also understand the dynamic properties of the peptides and lipids in membranes (cf. Table 2). Furthermore, as illustrated in the case of synergistic activities direct interactions between the peptides may or may not be of interest and reliable methods that can proof or disproof such hypotheses in membrane environments need to be established.

Advantage has been taken on rotational diffusion-dependent averaging of the spectral lines to develop a technique that monitors peptide oligomerisation in membranes (Aisenbrey and Bechinger, 2004a). This experiment is performed with the same samples used for structural analysis but in this experiment the samples are tilted by $90^{\circ}$ thereby aligning the bilayer normal perpendicular to the magnetic field direction. The experiments work well with ${ }^{2} \mathrm{H}_{3}$-alanine labelled peptides as in the tilted sample arrangement many different orientations of the $\mathrm{C} \alpha-\mathrm{C} \beta$ vector coexist and sum-up into a ${ }^{2} \mathrm{H}$ solid-state NMR spectrum. Whereas in the case of slow rotational diffusion such as is the case with oligomers the resulting spectra reflect the distribution of alignments and thereby distinct resonances, fast diffusion of monomers results in spectral averaging and a single quadrupolar splitting is observed. The size of the splitting is reduced by $-1 / 2$ times when compared to the sample orientation with the membrane normal parallel to the magnetic field direction. Related effects were found for the ${ }^{15} \mathrm{~N}$ chemical shift interactions albeit much larger aggregates would be required to interfere with averaging by 
rotational diffusion (Aisenbrey and Bechinger, 2004a). Typical correlation times for membrane-associated motions are listed in Table 2 and the corresponding motions graphically illustrated in Figure 6.

Notably dynamic processes also have an effect when the peptide alignment is calculated from solid-state NMR measurements. This is demonstrated when comparing Figures $2 \mathrm{~A}$ and $\mathrm{B}$ where the topological analysis is performed for a static peptide or when fluctuations around the helix long axis as well as of the tilt angle are taken into consideration. Even though the motions cover only a small range they need to be considered if the topological restrains are to be determined accurately.

Previous simulations have shown that in general determining the peptide topology in terms of tilt and rotational pitch angle (Fig. 2A) requires 3-4 well-chosen NMR restraints to align a given structure (Bechinger et al., 2011) although in some exceptional cases less data can be sufficient to unambiguously determine the peptide alignment (Henklein et al., 2000). By taking motions into consideration the number of restraints has to be correspondingly increased (Holt et al., 2010) albeit the structure and dynamics of a single residue of alamethicin has recently been obtained using three orientation-dependent parameters (Bertelsen et al., 2009).

During such analyses the motions of helical peptides have been described by wobbling of the helix as well as rotational movements around the helix long axis (Holt et al., 2010; Salnikov et al., 2010a; Strandberg et al., 2009a), a motional regime that has early on been introduced, for example to investigate the dynamics of ${ }^{2} \mathrm{H}$ exchange-labelled gramicidin $\mathrm{D}$ by deuterium solid-state NMR spectroscopy (Prosser and Davis, 1994). A recent investigation using a WALP model peptide indicates that six experimental parameters are required to determine the two orientational and motional parameters (tilt and rotational pitch angles as well as the wobbling motions around of these axes) whereby it has been noted that only quadrupolar splittings alone are not sufficiently complementary to perform such a detailed investigation (Holt et al., 2010). Furthermore the ${ }^{1} \mathrm{H}-{ }^{15} \mathrm{~N}$ dipolar coupling and the ${ }^{15} \mathrm{~N}$ chemical shifts provide very similar orientational restraints (Bechinger et al., 2011; Holt et al., 2010) and therefore combining ${ }^{2} \mathrm{H}$ quadrupolar splittings and ${ }^{15} \mathrm{~N}$ chemical shifts seems to be the method of choice (Aisenbrey and Bechinger, 2004b; Bertelsen et al., 2009; Holt et al., 2010). Interestingly, the motions can be described either by a Gaussian orientational distribution function or 'translated' into an order parameters where the peptide tilt angle fluctuations typically correspond to a value of 0.8 (Holt et al., 2010; Vermeer et al., 2007). 
When the inverse approach has been chosen and the effects of motions on the appearance of the solid-state NMR spectra analysed the ${ }^{15} \mathrm{~N}$ chemical shift of the peptide bond turns out to be a robust measure of approximate helical tilt angle in the presence or absence of motional averaging. In contrast, the deuterium quadrupolar splitting of ${ }^{2} \mathrm{H}_{3}$ labelled alanines are particularly sensitive to wobbling or rotational motions around the helix long axis and the resulting averaging effects (Aisenbrey and Bechinger, 2004a; Salnikov et al., 2010a). When such motional averaging is ignored during the structural analysis large (10$30^{\circ}$ ) systematic deviations of the calculated tilt angles can result (Ozdirekcan et al., 2007; Vostrikov et al., 2010). Indeed, during the analysis of ${ }^{2} \mathrm{H}$ solid-state NMR spectra models taking into consideration peptide dynamics by Gaussian distributions to describe the orientational variations around the helix main axis (azimuthal fluctuations) and/or explicit variations of the helix tilt angle (wagging fluctuations) resulted in more consistent results (Esteban-Martin et al., 2009; Ozdirekcan et al., 2007).

Whereas the ${ }^{2} \mathrm{H}$ quadrupolar splittings seem particularly sensitive to such motions when compared to ${ }^{15} \mathrm{~N}$ chemical shifts (Salnikov et al., 2010a) the effects of averaging on other anisotropic parameters such as ${ }^{15} \mathrm{~N}$ chemical shift and ${ }^{1} \mathrm{H}-{ }^{15} \mathrm{~N}$ dipolar couplings solid-state NMR spectra have also been simulated for helical and $\beta$-sheet polypeptide domains (Aisenbrey and Bechinger, 2004a; Bleile et al., 2005; Straus et al., 2003). Finally, it should be noted that side chain dynamics of membrane-associated proteins can be evaluated using wellselected pulse schemes and/or line shape analysis albeit so far less focus has been given to those NMR resonances (Aisenbrey et al., 2009; Chu et al., 2010; Xu et al., 2010).

\section{Conclusion and outlook}

Solid-state NMR spectroscopy is a powerful technique to investigate the high-resolution structures, topology, dynamics and lipid interactions of polypeptides when associated with liquid disordered lipid bilayers. The technique has the potential of a full-fledged structure determination also of membrane-associated antimicrobial peptides (Bechinger et al., 1993; Cross, 1997) and has already revealed many important details that have allowed us to revise the initial models for their mechanism of action. The technique reveals many details which are important for the understanding of their functioning including aspects of conformational exchange, mosaicity and dynamics. Importantly, the technique also allows the detailed analysis of the macroscopic phase properties of lipids, their dynamics, alignment distribution within oriented samples and their order parameter profiles at high resolution. 
The inherently low sensitivity of NMR spectroscopies requires that relatively large amounts of peptides, labelled with stable isotopes have to be prepared and purified. The line width and shape of the resulting NMR resonances are rich in conformational and topological information and the underlying heterogeneities often reflect functionally important properties of these polypeptide sequences (Aisenbrey et al., 2008; Aisenbrey et al., 2006a; Vogt et al., 2000). The conformational disorder is a function of lipid-peptide interactions, and of intrinsic conformational fluctuations, which are related to the primary structure and motional averaging of backbone and side chains. At the same time conformational heterogeneity results in significantly broadened lines and consequently low signal-to-noise and reduced resolution. Therefore, although the analysis of NMR line widths and line shapes are useful for understanding the function of membrane polypeptides (Su and Hong, 2011) they hamper the routine high-resolution structural analysis of membrane proteins using MAS or oriented solidstate NMR spectroscopy. To overcome some of these problems combining solid-state NMR approaches with information from solution state NMR spectroscopy in micelles or bicelles modelling has proven helpful.

An additional limitation that arises from broad lines is the reduction of the signal intensity of solid-state NMR spectra, as the resonances tend to be distributed over a broader width. These problems affect static oriented (and non-oriented) membrane samples more than any other NMR approach as the line width and spectral window is an order of magnitude increased when compared to MAS solid-state NMR spectroscopy. The potential application of dynamic nuclear polarisation, which results in NMR signal enhancements of potentially 2-3 orders of magnitude, also to oriented phospholipid bilayers, therefore bears considerable promise and has allowed to record NMR spectra of oriented membrane peptides in less than an hour that have been inaccessible under standard conditions (Salnikov et al., 2010b). With such new methods at hand the potential of solid-state NMR investigations of membrane-associated polypeptides will further increase.

\section{Acknowledgements}

The work of our laboratory was only possible with the financial support from the Agence Nationale de la Recherche, the Region Alsace, the CNRS and the University of Strasbourg. We are grateful to the Institute of Supramolecular Chemistry for hosting the laboratory. 


\section{TABLE 1: Sequences of antimicrobial peptides}

\section{Linear cationic sequences}

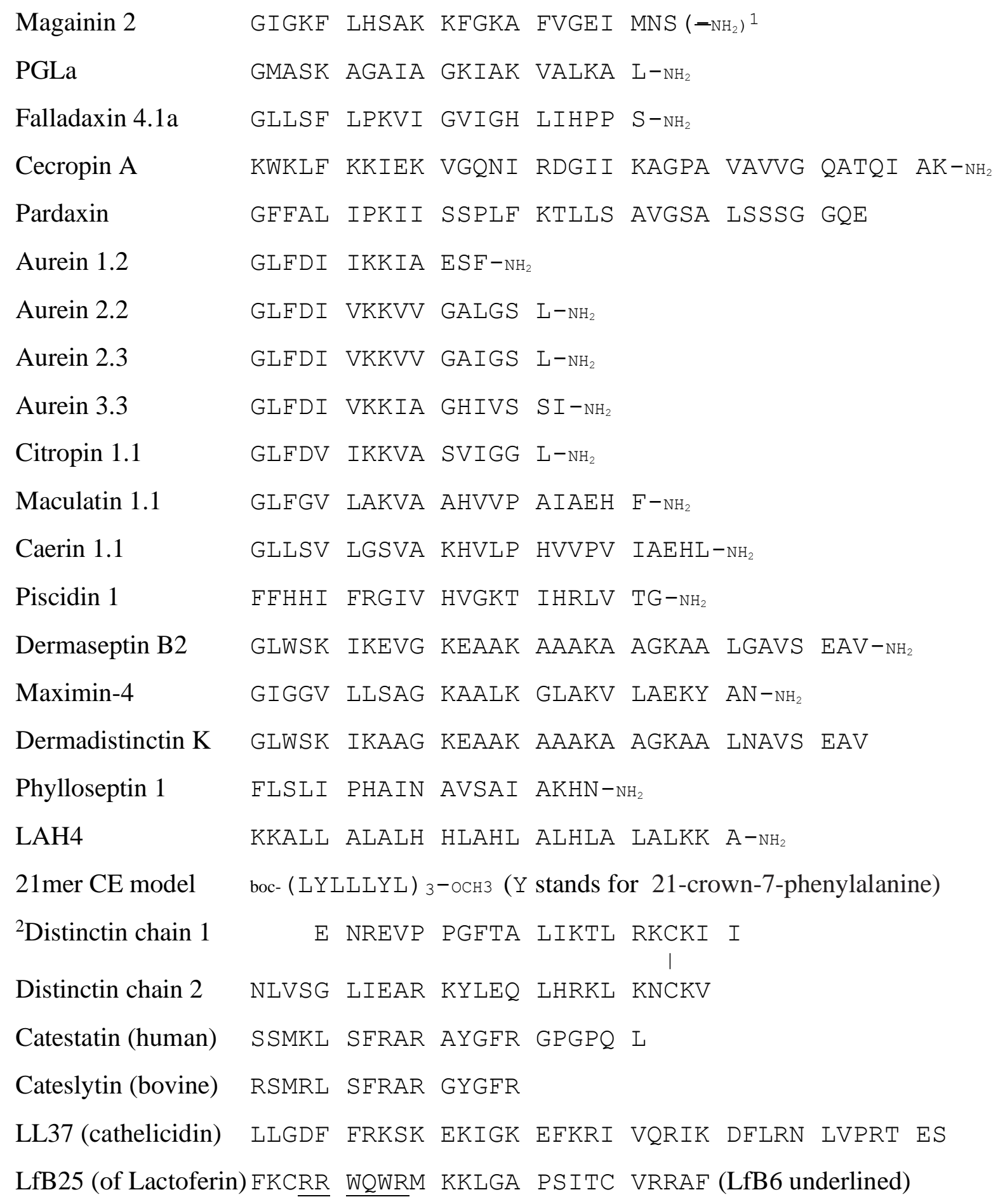


Rhesus $\Theta$ defensin 1 -GFCRC LCRRG VCRCI CTR- (circular)

\title{
$\underline{\text { Peptaibols }^{3}}$
}

Alamethicin (F50/7) Ac-Aib-Pro-Aib-Ala-Aib-Aib-Gln-Aib-Val-Aib-GlyLeu-Aib-Pro-Val-Aib-Aib-Gln-Gln-Phl

Ampullosporin A Ac-Trp-Ala-Aib-Aib-Leu-Aib-Gln-Aib-Aib-Aib-GlnLeu-Aib-Gln-Lol

Zervamicin IIB Ac-Trp-Ile-Gln-Iva-Ile-Thr-Aib-Hyp-Gln-Aib-HypAib-Pro-Phl

\begin{abstract}
${ }^{1}$ Although the natural magainin 1 an 2 sequences are not amidated, they gain an order of magnitude in antibacterial activities when the termini are protected (Chen et al., 1988), and are therefore much studied in the modified form.

${ }^{2}$ The two chains of distinctin have been aligned in such a manner to best visualize the covalent link between them.

${ }^{3}$ For better readability the peptaibols are listed by the three letter code. The following abbreviations are used for the non-standard residues of the latter compounds: Aib: $\alpha-$ aminoisobutyric acid, Iva: D-isovaline, Hyp: trans-4-hydroxy-L-proline, Phl: Lphenylalaninol, Lol: L-leucinol. The N- and C-terminal protecting groups are Ac- for acetyland $\mathrm{NH}_{2}$ for the carboxyamide, respectively.
\end{abstract}


(Table 2 should be represented in landscape format)

TABLE 2: Motions typically observed in lipid bilayers*

Motion

Correlation time in solution

isotropic contributions remain

Free rotation of PC headgroup $\left(\tau_{1}\right)$

Whole lipid molecule rotation $\left(\tau^{\mathrm{L}} \|\right)$

Whole lipid molecule fluctuations $\left(\tau^{\mathrm{L}} \perp\right)$

Lipid Lateral diffusion in membrane

Fenske and Jarrell, 1991; Picard et al., 1998)

vesicle radius e.g. $\left.\tau=\mathrm{R}^{2} /(6 \mathrm{D})\right)$

Small angle librations of bonds $\left(\tau_{2}, \tau_{3}\right)$

Collective bilayer motions ('ondulations')

Pitch angle variation for TM peptide $\left(\tau^{\mathrm{P}} \|\right)$ 1994)

Wobbling diffusion of entire peptide / 1994)

wagging fluctuation $\left(\tau_{\perp}^{\mathrm{P}_{\perp}}\right)$

Peptide topological transitions

Bechinger, 1996)

(from in-plane to transmembrane alignments) typical values

$$
10^{-12} \ldots 10^{-8} \mathrm{~s}
$$
reference / comments

(Mendz et al., 1988); only

$$
4 * 10^{-10} \ldots 7 * 10^{-10} \mathrm{~s}
$$

(Dufourc et al., 1992)

$\sim 4 * 10^{-9} \mathrm{~s}$

(Dufourc et al., 1992)

$\sim 4 * 10^{-8} \mathrm{~s}$

(Dufourc et al., 1992)

D $2 * 10^{-7} \mathrm{~cm}^{2} / \mathrm{s}$

(Dufourc et al., 1992;

correlation times depend on

(Dufourc et al., 1992)

$$
10^{-8} \ldots 10^{-6} \mathrm{~s}
$$

(Dufourc et al., 1992)

$10^{-9} \ldots 10^{-3} \mathrm{~s}$

(Prosser and Davis,

$\sim 7 * 10^{-9} \mathrm{~s}$

$\sim 6^{*} 10^{-6} \mathrm{~s}$

(Prosser and Davis,

$$
>10^{-4} \mathrm{~s}
$$

(Aisenbrey et al., 2006;

* In addition (rotational diffusion) motions of in plane oriented peptides of 20-26 amino acids in length interfere with ${ }^{1} \mathrm{H}_{-}{ }^{15} \mathrm{~N}$ cross polarization and/or ${ }^{1} \mathrm{H}$ decoupling suggesting motions in a regime covering $\tau$ of $10^{-4}$ to $10^{-5}$ s (Aisenbrey and Bechinger, 2004) 


\section{REFERENCES}

Ader, C., Pongs, O., Becker, S., Baldus, M., 2010. Protein dynamics detected in a membraneembedded potassium channel using two-dimensional solid-state NMR spectroscopy. Biochim Biophys Acta 1798, 286-290.

Aisenbrey, C., Bechinger, B., 2004a. Investigations of peptide rotational diffusion in aligned membranes by $2 \mathrm{H}$ and $15 \mathrm{~N}$ solid-state NMR spectroscopy J.Am.Chem.Soc. 126, 1667616683.

Aisenbrey, C., Bechinger, B., 2004b. Tilt and rotational pitch angles of membrane-inserted polypeptides from combined $15 \mathrm{~N}$ and $2 \mathrm{H}$ solid-state NMR spectroscopy Biochemistry-Us 43, 10502-10512.

Aisenbrey, C., Bertani, P., Bechinger, B., 2010. Solid-state NMR investigations of membrane-associated antimicrobial peptides, In: Guiliani, A., Rinaldi, A.C. (Eds.), Antimicrobial Peptides Humana Press, Springer, N.Y., pp. 209-234.

Aisenbrey, C., Cusan, M., Lambotte, S., Jasperse, P., Georgescu, J., Harzer, U., Bechinger, B., 2008. Specific isotope labeling of colicin E1 and B channel domains for membrane topological analysis by oriented solid-state NMR spectroscopy. Chem.Bio.Chem. 9, 944-951.

Aisenbrey, C., Harzer, U., Bauer-Manz, G., Bär, G., Husmal Chotimah, I.N., Bertani, P., Sizun, C., Kuhn, A., Bechinger, B., 2006a. Proton-decoupled 15N and 31P solid-state NMR investigations of the Pf3 coat protein in oriented phospholipid bilayers FEBS J. 273, 817828.

Aisenbrey, C., Kinder, R., Goormaghtigh, E., Ruysschaert, J.M., Bechinger, B., 2006 b. Interactions involved in the realignment of membrane-associated helices: An investigation using oriented solid-state NMR and ATR-FTIR spectroscopies topologies J. Biol. Chem. 281, 7708-7716.

Aisenbrey, C., Prongidi-Fix, L., Chenal, A., Gillet, D., Bechinger, B., 2009. Side chain resonances in static oriented proton-decoupled $15 \mathrm{~N}$ solid-state NMR spectra of membrane proteins. J.Am.Chem.Soc. 131, 6340-6341.

Aisenbrey, C., Sizun, C., Koch, J., Herget, M., Abele, U., Bechinger, B., Tampe, R., 2006c. Structure and dynamics of membrane-associated ICP47, a viral inhibitor of the MHC I antigen-processing machinery. J. Biol. Chem. 281, 30365-30372.

Aisenbrey, C., Sudheendra, U.S., Ridley, H., Bertani, P., Marquette, A., Nedelkina, S., Lakey, J.H., Bechinger, B., 2007. Helix orientations in membrane-associated Bcl-X L determined by 15 N solid-state NMR spectroscopy. Eur.Biophys.J. 36, 451-460.

Andronesi, O.C., Becker, S., Seidel, K., Heise, H., Young, H.S., Baldus, M., 2005.

Determination of membrane protein structure and dynamics by magic-angle-spinning solidstate NMR spectroscopy. J Am Chem Soc 127, 12965-12974.

Aussenac, F., Tavares, M., Dufourc, E.J., 2003. Cholesterol dynamics in membranes of raft composition: a molecular point of view from $2 \mathrm{H}$ and $31 \mathrm{P}$ solid-state NMR. Biochemistry-Us 42, 1383-1390.

Bak, M., Bywater, R.P., Hohwy, M., Thomsen, J.K., Adelhorst, K., Jakobsen, H.J., Sorensen, O.W., Nielsen, N.C., 2001. Conformation of alamethicin in oriented phospholipid bilayers determined by N-15 solid-state nuclear magnetic resonance. Biophys.J. 81, 1684-1698. 
Baldus, M., 2006. Solid-state NMR spectroscopy: molecular structure and organization at the atomic level. Angew.Chem Int.Ed Engl. 45, 1186-1188.

Balla, M.S., Bowie, J.H., Separovic, F., 2004. Solid-state NMR study of antimicrobial peptides from Australian frogs in phospholipid membranes. Eur Biophys J. 33, 109-116.

Barsukov, L.I., Victorov, A.V., Vasilenko, I.A., Evstigneeva, R.P., Bergelson, L.D., 1980. Investigation of the inside-Outside Distribution, Intermembrane Exchange and Transbilayer Movement of Phospholipids in Sonicated Vesicles by Shift-Reagent Nmr. Biochimica Et Biophysica Acta 598, 153-168.

Batchelder, L.S., Niu, H., Torchia, D.A., 1983. Methyl reorientation in polycrystalline amino acids and peptides: A 2H NMR spin lattice relaxation study. J.Am.Chem.Soc. 105, 22282231.

Bechinger, B., 1996. Towards membrane protein design: $\mathrm{pH}$ dependent topology of histidinecontaining polypeptides. J.Mol.Biol. 263, 768-775.

Bechinger, B., 1997. Structure and Functions of Channel-Forming Polypeptides: Magainins, Cecropins, Melittin and Alamethicin. J Membrane Biol 156, 197-211.

Bechinger, B., 1999. The structure, dynamics and orientation of antimicrobial peptides in membranes by solid-state NMR spectroscopy. Biochimica et Biophysica Acta 1462, 157-183.

Bechinger, B., 2001. Membrane insertion and orientation of polyalanine peptides: A $15 \mathrm{~N}$ solid-state NMR spectroscopy investigation. Biophys.J. 82, 2251-2256.

Bechinger, B., 2005. Detergent-like properties of magainin antibiotic peptides: A 31P solidstate NMR study. Biochimica et Biophysica Acta 1712, 101-108.

Bechinger, B., 2009. Rationalizing the membrane interactions of cationic amphipathic antimicrobial peptides by their molecular shape. Cur. Opin. Colloid Interface Scie., Surfactants $14,349-355$

Bechinger, B., 2011. Insights into the mechanisms of action of host defence peptides from biophysical and structural investigations. J Pept Sci 17, 306-314.

Bechinger, B., Bertani, P., Werten, S., Mendonca de Moraes, C., Aisenbrey, C., Mason, A.J., Perrone, B., Prudhon, M., Sudheendra, U.S., Vidovic, V., Miguel, C., 2010. The structural and topological analysis of membrane polypeptides by oriented solid-state NMR spectroscopy: Sample preparation and theory, Membrane-active peptides: Methods and results on structure and function. International University Line, La Jolla, California, USA, pp. $196-215$

Bechinger, B., Kim, Y., Chirlian, L.E., Gesell, J., Neumann, J.M., Montal, M., Tomich, J., Zasloff, M., Opella, S.J., 1991. Orientations of amphipathic helical peptides in membrane bilayers determined by solid- state NMR spectroscopy. J.Biomol.NMR 1, 167-173.

Bechinger, B., Kinder, R., Helmle, M., Vogt, T.B., Harzer, U., Schinzel, S., 1999a. Peptide structural analysis by solid-state NMR spectroscopy. Biopolymers 51, 174-190.

Bechinger, B., Lohner, K., 2006. Detergent-like action of linear cationic membrane-active antibiotic peptides. Biochim Biophys Acta 1758, 1529-1539.

Bechinger, B., Resende, J.M., Aisenbrey, C., 2011. The structural and topological analysis of membrane-associated polypeptides by oriented solid-state NMR spectroscopy: Established concepts and novel developments. Biophys Chem 153, 115-125. 
Bechinger, B., Ruysschaert, J.M., Goormaghtigh, E., 1999b. Membrane Helix Orientation from Linear Dichroism of Infrared Attenuated Total Reflection Spectra. Biophys.J. 76, 552563.

Bechinger, B., Shon, K., Eck, H., Zasloff, M., Opella, S.J., 1990. NMR studies of magainin peptide antibiotics in membranes. Hoppe-Seylers Zeitschrift f̊̊r Biol.Chem. 371, 758-758.

Bechinger, B., Sizun, C., 2003. Alignment and structural analysis of membrane polypeptides by $15 \mathrm{~N}$ and 31P solid-state NMR spectroscopy Concepts in Magnetic Resonance 18A, 130 145

Bechinger, B., Skladnev, D.A., Ogrel, A., Li, X., Swischewa, N.V., Ovchinnikova, T.V., O'Neil, J.D.J., Raap, J., 2001. 15 N and 31 P solid-state NMR investigations on the orientation of zervamicin II and alamethicin in phosphatidylcholine membranes. Biochemistry-Us 40, 9428-9437.

Bechinger, B., Zasloff, M., Opella, S.J., 1992. Structure and Interactions of Magainin Antibiotic Peptides in Lipid Bilayers: A Solid-State NMR Investigation. Biophys.J. 62, 12-14.

Bechinger, B., Zasloff, M., Opella, S.J., 1993. Structure and orientation of the antibiotic peptide magainin in membranes by solid-state NMR spectroscopy. Protein Sci 2, 2077-2084.

Bechinger, B., Zasloff, M., Opella, S.J., 1998. Structure and Dynamics of the Antibiotic Peptide PGLa in Membranes by Multidimensional Solution and Solid-State NMR Spectroscopy. Biophys.J. 74, 981-987.

Beevers, A.J., Dixon, A.M., 2010. Helical membrane peptides to modulate cell function. Chem Soc Rev 39, 2146-2157.

Bello, J., Bello, H.R., Granados, E., 1982. Conformation and aggregation of melittin: dependence on $\mathrm{pH}$ and concentration. Biochemistry-Us 21, 461-465.

Benko-Iseppon, A.M., Galdino, S.L., Calsa, T., Jr., Kido, E.A., Tossi, A., Belarmino, L.C., Crovella, S., 2010. Overview on plant antimicrobial peptides. Curr Protein Pept Sci 11, 181188.

Bertelsen, K., Paaske, B., Thogersen, L., Tajkhorshid, E., Schiott, B., Skrydstrup, T., Nielsen, N.C., Vosegaard, T., 2009. Residue-specific information about the dynamics of antimicrobial peptides from (1)H-(15)N and (2)H solid-state NMR spectroscopy. J Am Chem Soc 131, 18335-18342.

Bertelsen, K., Pedersen, J.M., Rasmussen, B.S., Skrydstrup, T., Nielsen, N.C., Vosegaard, T., 2007. Membrane-bound conformation of peptaibols with methyl-deuterated alpha-amino isobutyric acids by $2 \mathrm{H}$ magic angle spinning solid-state NMR spectroscopy. J Am.Chem Soc. $129,14717-14723$.

Bleile, D.W., Scott, W.R., Straus, S.K., 2005. Can PISEMA experiments be used to extract structural parameters for mobile beta-barrels? J Biomol NMR 32, 101-111.

Bockmann, A., 2008. 3D protein structures by solid-state NMR spectroscopy: ready for high resolution. Angew Chem Int Ed Engl 47, 6110-6113.

Bolintineanu, D., Hazrati, E., Davis, H.T., Lehrer, R.I., Kaznessis, Y.N., 2010. Antimicrobial mechanism of pore-forming protegrin peptides: 100 pores to kill E. coli. Peptides 31, 1-8.

Boman, H.G., 2003. Antibacterial peptides: basic facts and emerging concepts. J Intern Med 254, 197-215. 
Boman, H.G., Hultmark, D., 1987. Cell-free immunity in insects. Ann.Rev.Microbiol. 41, 103-126.

Bourbigot, S., Fardy, L., Waring, A.J., Yeaman, M.R., Booth, V., 2009. Structure of Chemokine-Derived Antimicrobial Peptide Interleukin-8 alpha and Interaction with Detergent Micelles and Oriented Lipid Bilayers. Biochemistry-Us 48, 10509-10521.

Brand, G.D., Leite, J.R., de Sa Mandel, S.M., Mesquita, D.A., Silva, L.P., Prates, M.V., Barbosa, E.A., Vinecky, F., Martins, G.R., Galasso, J.H., Kuckelhaus, S.A., Sampaio, R.N., Furtado, J.R., Jr., Andrade, A.C., Bloch, C., Jr., 2006. Novel dermaseptins from

Phyllomedusa hypochondrialis (Amphibia). Biochem Biophys Res Commun. 347, 739-746.

Brogden, K.A., 2005. Antimicrobial peptides: pore formers or metabolic inhibitors in bacteria? Nat.Rev.Microbiol. 3, 238-250.

Brunner, E., 2001. Residual Dipolar couplings in protein NMR. Concepts in Magnetic Resonance 13, 238-259.

Bulet, P., Stocklin, R., Menin, L., 2004. Anti-microbial peptides: from invertebrates to vertebrates. Immunol Rev 198, 169-184.

Cady, S.D., Goodman, C., Tatko, C.D., DeGrado, W.F., Hong, M., 2007. Determining the orientation of uniaxially rotating membrane proteins using unoriented samples: a $2 \mathrm{H}, 13 \mathrm{C}$, and $15 \mathrm{~N}$ solid-state NMR investigation of the dynamics and orientation of a transmembrane helical bundle. J Am Chem Soc 129, 5719-5729.

Cady, S.D., Schmidt-Rohr, K., Wang, J., Soto, C.S., Degrado, W.F., Hong, M., 2010.

Structure of the amantadine binding site of influenza M2 proton channels in lipid bilayers. Nature 463, 689-692.

Castellani, F., van Rossum, B., Diehl, A., Schubert, M., Rehbein, K., Oschkinat, H., 2002. Structure of a protein determined by solid-state magic-angle-spinning NMR spectroscopy. Nature 420, 98-102.

Chekmenev, E.Y., Jones, S.M., Nikolayeva, Y.N., Vollmar, B.S., Wagner, T.J., Gor'kov, P.L., Brey, W.W., Manion, M.N., Daugherty, K.C., Cotten, M., 2006. High-field NMR studies of molecular recognition and structure-function relationships in antimicrobial piscidins at the water-lipid bilayer interface. J Am Chem Soc 128, 5308-5309.

Chen, H.-C., Brown, J.H., Morell, J.L., Huang, C.M., 1988. Synthetic magainin analogues with improved antimicrbial activity. FEBS Letters 236, 462-466.

Cheng, J.T.J., Hale, J.D., Elliot, M., Hancock, R.E.W., Straus, S.K., 2009. Effect of Membrane Composition on Antimicrobial Peptides Aurein 2.2 and 2.3 From Australian Southern Bell Frogs. Biophys J 96, 552-565.

Christensen, B., Fink, J., Merrifield, R.B., Mauzerall, D., 1988. Channel-forming properties of cecropins and related model compounds incorporated into planar lipid membranes.

Proceedings of the National Academy of Sciences USA 85, 5072-5076.

Chu, S., Coey, A.T., Lorigan, G.A., 2010. Solid-state (2)H and (15)N NMR studies of sidechain and backbone dynamics of phospholamban in lipid bilayers: investigation of the N27A mutation. Biochim Biophys Acta 1798, 210-215.

Columbus, L., Lipfert, J., Jambunathan, K., Fox, D.A., Sim, A.Y., Doniach, S., Lesley, S.A., 2009. Mixing and matching detergents for membrane protein NMR structure determination. J Am Chem Soc 131, 7320-7326. 
Cross, T.A., 1997. Solid-state nuclear magnetic resonance characterization of gramicidin channel structure. Method Enzymol 289, 672-696.

Cruciani, R.A., Stanley, E.F., Zasloff, M., Lewis, D.L., Barker, J.L., 1988. The Antibiotic Magainin II from the African Clawed Frog Forms an Anion Permeable Ionophore in Artificial Membranes. Biophys J 53, 9a.

Cullis, P.R., De Kruijff, B., 1979. Lipid Polymorphism and the Functional Roles of Lipids in Biological Membranes. Biochimica et Biophysica Acta 559, 399-420.

Dathe, M., Nikolenko, H., Meyer, J., Beyermann, M., Bienert, M., 2001. Optimization of the antimicrobial activity of magainin peptides by modification of charge. FEBS Lett 501, 146150 .

Davis, J.H., 1983. The description of membrane lipid conformation, order and dynamics by 2 H-NMR. Biochimica et Biophysica Acta 737, 117-171.

Davis, J.H., Auger, M., 1999. Static and magic angle spinning NMR of membrane peptides and proteins. Progress in NMR Spectroscopy 35, 1-84.

De Angelis, A.A., Grant, C.V., Baxter, M.K., McGavin, J.A., Opella, S.J., Cotten, M.L., 2011. Amphipathic Antimicrobial Piscidin in Magnetically Aligned Lipid Bilayers. Biophys J 101, 1086-1094.

Dennison, S.R., Whittaker, M., Harris, F., Phoenix, D.A., 2006. Anticancer alpha-helical peptides and structure/function relationships underpinning their interactions with tumour cell membranes. Curr Protein Pept Sci 7, 487-499.

Diamond, G., Beckloff, N., Weinberg, A., Kisich, K.O., 2009. The roles of antimicrobial peptides in innate host defense. Curr Pharm Des 15, 2377-2392.

Douliez, J.P., Bechinger, B., Davis, J.H., Dufourc, E.J., 1996. C-C bond order parameters from 2H and 13C solid-state NM. J Phys Chem-Us 100, 17083-17086.

Douliez, J.P., Belloca, A.M., Dufourc, E.J., 1994. Effect of vesicle size, polydispersity and multilayering on solid-state $31 \mathrm{P}$ - and 2 H-NMR spectra. J.Chim.Phys. 91, 874-880.

Drechsler, A., Anderluh, G., Norton, R.S., Separovic, F., 2010. Solid-state NMR study of membrane interactions of the pore-forming cytolysin, equinatoxin II. Biochim Biophys Acta 1798, 244-251.

Duclohier, H., 2010. Antimicrobial peptides and peptaibols, substitutes for conventional antibiotics. Curr Pharm Des 16, 3212-3223.

Dufourc, E.J., 2008. Sterols and membrane dynamics. J.Chem.Biol. 1, 63-77.

Dufourc, E.J., Mayer, C., Stohrer, J., Althoff, G., Kothe, G., 1992. Dynamics of Phosphate Head Groups in Biomembranes - Comprehensive Analysis Using P-31 Nuclear-MagneticResonance Lineshape and Relaxation-Time Measurements. Biophys J 61, $42-57$.

Epand, R.F., Maloy, W.L., Ramamoorthy, A., Epand, R.M., 2010. Probing the "charge cluster mechanism" in amphipathic helical cationic antimicrobial peptides. Biochemistry-Us 49, 4076-4084.

Esteban-Martin, S., Gimenez, D., Fuertes, G., Salgado, J., 2009. Orientational landscapes of peptides in membranes: prediction of (2)H NMR couplings in a dynamic context.

Biochemistry-Us 48, 11441-11448. 
Etzkorn, M., Seidel, K., Li, L., Martell, S., Geyer, M., Engelhard, M., Baldus, M., 2010. Complex formation and light activation in membrane-embedded sensory rhodopsin II as seen by solid-state NMR spectroscopy. Structure 18, 293-300.

Fenske, D.B., Jarrell, H.C., 1991. Phosphoroous-31 Two-Dimensional Solid-State Exchange NMR. Biophys J 59, 55-69.

Fernandez, D.I., Gehman, J.D., Separovic, F., 2009. Membrane interactions of antimicrobial peptides from Australian frogs. Biochim Biophys Acta 1788, 1630-1638.

Fernandez, D.I., Sani, M.A., Gehman, J.D., Hahm, K.S., Separovic, F., 2011. Interactions of a synthetic Leu-Lys-rich antimicrobial peptide with phospholipid bilayers. Eur Biophys J Biophy 40, 471-480.

Gamier-Lhomme, M., Grelard, A., Byrne, R.D., Loudet, C., Dufourc, E.J., Larijani, B., 2007. Probing the dynamics of intact cells and nuclear envelope precursor membrane vesicles by deuterium solid state NMR spectroscopy. Bba-Biomembranes 1768, 2516-2527.

Gautier, A., Mott, H.R., Bostock, M.J., Kirkpatrick, J.P., Nietlispach, D., 2010. Structure determination of the seven-helix transmembrane receptor sensory rhodopsin II by solution NMR spectroscopy. Nat Struct Mol Biol 17, 768-774.

Gawrisch, K., Eldho, N.V., Polozov, I.V., 2002. Novel NMR tools to study the structure and dynamics of biomembranes. Chem.Phys.Lipids 116, 135-151.

Gayen, A., Mukhopadhyay, C., 2008. Evidence for effect of GM1 on opioid peptide conformation: NMR study on leucine enkephalin in ganglioside-containing isotropic phospholipid bicelles. Langmuir 24, 5422-5432.

Gehman, J.D., Luc, F., Hall, K., Lee, T.H., Boland, M.P., Pukala, T.L., Bowie, J.H., Aguilar, M.I., Separovic, F., 2008. Effect of antimicrobial peptides from Australian tree frogs on anionic phospholipid membranes. Biochemistry-Us 47, 8557-8565.

Georgescu, J., Bechinger, B., 2010. NMR structures of the histidine-rich peptide LAH4 in micellar environments: membrane insertion, $\mathrm{pH}$-dependent mode of antimicrobial action and DNA transfection. Biophys J 99, 2507-2515

Giovannini, M.G., Poulter, L., Gibson, B.W., Williams, D.H., 1987. Biosynthesis and degradation of peptides derived from Xenopus laevis prohormones. Biochemical Journal 243, 113-120.

Giuliani, A., Pirri, G., Bozzi, A., Di Giulio, A., Aschi, M., Rinaldi, A.C., 2008. Antimicrobial peptides: natural templates for synthetic membrane-active compounds. Cell Mol Life Sci 65, 2450-2460.

Glaubitz, C., Watts, A., 1998. Magic angle oriented sample spinning (MAOSS) - A new approach toward biomembrane studies. J.Magn.Reson. 130, 305-316.

Goldmann, W.H., Isenberg, G., Marsh, D., Bechinger, B., 2007. Cytoskeletal proteins meet lipid bilayers In: Tien, H.T. (Ed.), Planar Lipid Bilayers and Their Applications: Recent Progress.

Gottler, L.M., Ramamoorthy, A., 2009. Structure, membrane orientation, mechanism, and function of pexiganan--a highly potent antimicrobial peptide designed from magainin. Biochim Biophys Acta 1788, 1680-1686.

Gregory, S.M., Cavenaugh, A., Journigan, V., Pokorny, A., Almeida, P.F.F., 2008. A quantitative model for the all-or-none permeabilization of phospholipid vesicles by the antimicrobial peptide cecropin A. Biophys.J. 94, 1667-1680. 
Griffin, R.G., 1981. Solid-state nuclear magnetic resonance of lipid bilayers. Method Enzymol 72, 108-173.

Hadley, E.B., Hancock, R.E., 2010. Strategies for the Discovery and Advancement of Novel Cationic Antimicrobial Peptides. Curr Top Med Chem 10, 1872-1881.

Hallock, K.J., Henzler, W.K., Lee, D.K., Ramamoorthy, A., 2002a. An innovative procedure using a sublimable solid to align lipid bilayers for solid-state NMR studies. Biophys J 82, 2499-2503.

Hallock, K.J., Lee, D.K., Omnaas, J., Mosberg, H.I., Ramamoorthy, A., 2002b. Membrane composition determines pardaxin's mechanism of lipid bilayer disruption. Biophys J 83, 10041013.

Hallock, K.J., Lee, D.K., Ramamoorthy, A., 2003. MSI-78, an Analogue of the Magainin Antimicrobial Peptides, Disrupts Lipid Bilayer Structure via Positive Curvature Strain. Biophys J 84, 3052-3060.

Haney, E.F., Hunter, H.N., Matsuzaki, K., Vogel, H.J., 2009. Solution NMR studies of amphibian antimicrobial peptides: linking structure to function? Biochim Biophys Acta 1788, 1639-1655.

Harzer, U., Bechinger, B., 2000. The alignment of lysine-anchored membrane peptides under conditions of hydrophobic mismatch: A CD, $15 \mathrm{~N}$ and $31 \mathrm{P}$ solid-state NMR spectroscopy investigation. Biochemistry-Us 39, 13106-13114.

Heinzmann, R., Grage, S.L., Schalck, C., Burck, J., Banoczi, Z., Toke, O., Ulrich, A.S., 2011. A kinked antimicrobial peptide from Bombina maxima. II. Behavior in phospholipid bilayers. Eur Biophys J Biophy 40, 463-470.

Henklein, P., Kinder, R., Schubert, U., Bechinger, B., 2000. Membrane interactions and alignment of the structures within HIV-1 Vpu cytoplasmic domain: Effect of phosphorylation of serines 52 and 56. FEBS Lett. 482, 220-224.

Henzler-Wildman, K.A., Martinez, G.V., Brown, M.F., Ramamoorthy, A., 2004. Perturbation of the hydrophobic core of lipid bilayers by the human antimicrobial peptide LL-37.

Biochemistry-Us 43, 8459-8469.

Hiller, M., Higman, V.A., Jehle, S., van Rossum, B.J., Kuhlbrandt, W., Oschkinat, H., 2008. [2,3-(13)C]-labeling of aromatic residues--getting a head start in the magic-angle-spinning NMR assignment of membrane proteins. J Am Chem Soc 130, 408-409.

Hirschinger, J., Raya, J., Perrone, B., Bechinger, B., 2011. Chemical shift powder spectra obtained by using ROtor-Directed Exchange of Orientations Cross-Polarization (RODEOCP). Chem Phys Lett 508, 155-164.

Hoffmann, W., Richter, K., Kreil, G., 1983. A novel peptide designated PYL abd its precursor as predicted from cloned mRNA of Xenopus laevis skin. EMBO J. 2, 711-714.

Holt, A., Rougier, L., Reat, V., Jolibois, F., Saurel, O., Czaplicki, J., Killian, J.A., Milon, A., 2010. Order parameters of a transmembrane helix in a fluid bilayer: case study of a WALP peptide. Biophys J 98, 1864-1872.

Holzl, M.A., Hofer, J., Steinberger, P., Pfistershammer, K., Zlabinger, G.J., 2008. Host antimicrobial proteins as endogenous immunomodulators. Immunol Lett 119, 4-11.

Hong, M., 2007. Structure, topology, and dynamics of membrane peptides and proteins from solid-state NMR Spectroscopy. Journal of Physical Chemistry B 111, 10340-10351. 
Hong, M., Su, Y., 2011. Structure and dynamics of cationic membrane peptides and proteins: insights from solid-state NMR. Protein Sci 20, 641-655.

Hu, W.G., Som, A., Tew, G.N., 2011. Interaction between Lipids and Antimicrobial Oligomers Studied by Solid-State NMR. Journal of Physical Chemistry B 115, 8474-8480.

Huang, H.W., 2000. Action of antimicrobial peptides: Two-state model. Biochemistry-Us 39, 8347-8352.

Hwang, P.M., Vogel, H.J., 1998. Structure-function relationships of antimicrobial peptides. Biochem.Cell Biol. 76, 235-246.

Ieronimo, M., Afonin, S., Koch, K., Berditsch, M., Wadhwani, P., Ulrich, A.S., 2010. (19)F NMR Analysis of the Antimicrobial Peptide PGLa Bound to Native Cell Membranes from Bacterial Protoplasts and Human Erythrocytes. J Am Chem Soc 132, 8822-+.

Israelachvili, J.N., Marcelja, S., Horn, R.G., 1980. Physical principles of membrane organization. Q.Rev.Biophys. 13, 121-200.

Jean-Francois, F., Desbat, B., Dufourc, E.J., 2009. Selectivity of cateslytin for fungi: the role of acidic lipid-ergosterol membrane fluidity in antimicrobial action. Faseb J.

Juhasz, J., Sharom, F.J., Davis, J.H., 2009. Quantitative characterization of coexisting phases in DOPC/DPPC/cholesterol mixtures: comparing confocal fluorescence microscopy and deuterium nuclear magnetic resonance. Biochim Biophys Acta 1788, 2541-2552.

Kelusky, E.C., Dufourc, E.J., Smith, I.C., 1983. Direct observation of molecular ordering of cholesterol in human erythrocyte membranes. Biochimica et Biophysica Acta 735, 302-304.

Kim, C., Spano, J., Park, E.K., Wi, S., 2009. Evidence of pores and thinned lipid bilayers induced in oriented lipid membranes interacting with the antimicrobial peptides, magainin-2 and aurein-3.3. Bba-Biomembranes 1788, 1482-1496.

Kim, S., Cross, T.A., 2004. 2D solid state NMR spectral simulation of 3(10), alpha, and pihelices. J Magn Reson 168, 187-193.

Kindrachuk, J., Napper, S., 2010. Structure-activity relationships of multifunctional host defence peptides. Mini Rev Med Chem 10, 596-614.

Kiss, G., Michl, H., 1962. öber das Giftsekret der Gelbbauchunke Bombina variegata L Toxicon (Oxford) 1, 33-39.

Kouzayha, A., Wattraint, O., Sarazin, C., 2009. Interactions of two transmembrane peptides in supported lipid bilayers studied by a (31)P and (15)N MAOSS NMR strategy. Biochimie 91, 774-778.

Krabben, L., van Rossum, B.J., Jehle, S., Bocharov, E., Lyukmanova, E.N., Schulga, A.A., Arseniev, A., Hucho, F., Oschkinat, H., 2009. Loop 3 of short neurotoxin II is an additional interaction site with membrane-bound nicotinic acetylcholine receptor as detected by solidstate NMR spectroscopy. J Mol Biol 390, 662-671.

Kuroda, K., DeGrado, W.F., 2005. Amphiphilic polymethacrylate derivatives as antimicrobial agents. J Am Chem Soc 127, 4128-4129.

Lange, V., Becker-Baldus, J., Kunert, B., van Rossum, B.J., Casagrande, F., Engel, A., Roske, Y., Scheffel, F.M., Schneider, E., Oschkinat, H., 2010. A MAS NMR study of the bacterial ABC transporter ArtMP. Chembiochem 11, 547-555. 
Lee, D., Walter, K.F., Bruckner, A.K., Hilty, C., Becker, S., Griesinger, C., 2008. Bilayer in small bicelles revealed by lipid-protein interactions using NMR spectroscopy. J Am Chem Soc 130, 13822-13823.

Leitgeb, B., Szekeres, A., Manczinger, L., Vagvolgyi, C., Kredics, L., 2007. The history of alamethicin: a review of the most extensively studied peptaibol. Chem Biodivers. 4, 10271051.

Liu, S.P., Zhou, L., Lakshminarayanan, R., Beuerman, R.W., 2010. Multivalent Antimicrobial Peptides as Therapeutics: Design Principles and Structural Diversities. Int J Pept Res Ther 16, 199-213.

Loudet, C., Manet, S., Gineste, S., Oda, R., Achard, M.F., Dufourc, E.J., 2007. Biphenyl bicelle disks align perpendicular to magnetic fields on large temperature scales: a study combining synthesis, solid-state NMR, TEM, and SAXS. Biophys J 92, 3949-3959.

Luca, S., White, J.F., Sohal, A.K., Filippov, D.V., van Boom, J.H., Grisshammer, R., Baldus, M., 2003. The conformation of neurotensin bound to its $G$ protein-coupled receptor. Proc Natl Acad Sci U S A 100, 10706-10711.

Ludtke, S., He, K., Huang, H., 1995. Membrane thinning caused by magainin 2. Biochemistry-Us 34, 16764-16769.

Ludtke, S.J., He, K., Heller, W.T., Harroun, T.A., Yang, L., Huang, H.W., 1996. Membrane pores induced by magainin. Biochemistry-Us 35, 13723-13728.

Mader, J.S., Hoskin, D.W., 2006. Cationic antimicrobial peptides as novel cytotoxic agents for cancer treatment. Expert Opin Investig Drugs 15, 933-946.

Makovitzki, A., Baram, J., Shai, Y., 2008. Antimicrobial lipopolypeptides composed of palmitoyl Di- and tricationic peptides: in vitro and in vivo activities, self-assembly to nanostructures, and a plausible mode of action. Biochemistry-Us 47, 10630-10636.

Marassi, F.M., Ma, C., Gesell, J.J., Opella, S.J., 2000. Three-dimensional solid-state NMR spectroscopy is essential for resolution of resonances from in-plane residues in uniformly (15)N-labeled helical membrane proteins in oriented lipid bilayers. Journal of Magnetic Resonance 144, 156-161.

Marquette, A., Mason, A.J., Bechinger, B., 2008. Aggregation and membrane permeabilizing properties of designed histidine-containing cationic linear peptide antibiotics. J Pept.Sci 14, 488-495.

Marsan, M.P., Muller, I., Ramos, C., Rodriguez, F., Dufourc, E.J., Czaplicki, J., Milon, A., 1999. Cholesterol orientation and dynamics in dimyristoylphosphatidylcholine bilayers: A solid state deuterium NMR analysis. Biophys.J. 76, 351-359.

Marsh, D., 2008. Energetics of hydrophobic matching in lipid-protein interactions. Biophys J.

Mason, A.J., Bertani, P., Moulay, G., Marquette, A., Perrone, B., Drake, A.F., Kichler, A., Bechinger, B., 2007. Membrane Interaction of Chrysophsin-1, a Histidine-Rich Antimicrobial Peptide from Red Sea Bream. Biochemistry-Us 46, 15175-15187.

Mason, A.J., Martinez, A., Glaubitz, C., Danos, O., Kichler, A., Bechinger, B., 2006. The antibiotic and DNA-transfecting peptide LAH4 selectively associates with, and disorders, anionic lipids in mixed membranes. FASEB J. 20, 320-322.

Mason, A.J., Moussaoui, W., Abdelrhaman, T., Boukhari, A., Bertani, P., Marquette, A., Shooshtarizaheh, P., Moulay, G., Boehm, N., Guerold, B., Sawers, R.J.H., Kichler, A., MetzBoutigue, M.H., Candolfi, E., Prevost, G., Bechinger, B., 2009. Structural determinants of 
antimicrobial and antiplasmodial activity and selectivity in histidine rich amphipathic cationic peptides. J. Biol. Chem. 284, 119-133.

Matsuzaki, K., 1998. Magainins as paradigm for the mode of action of pore forming polypeptides. Biochimica et Biophysica Acta 1376, 391-400.

Matsuzaki, K., Harada, M., Funakoshi, S., Fujii, N., Miyajima, K., 1991. Physicochemical Determinants for the Interactions of Magainins 1 and 2 with Acidic Lipid Bilayers. Biochimica et Biophysica Acta 1063, 162-170.

Matsuzaki, K., Mitani, Y., Akada, K., Murase, O., Yoneyama, S., Zasloff, M., Miyajima, K., 1998. Mechanism of synergism between antimicrobial peptides magainin 2 and PGLa. Biochemistry-Us 37, 15144-15153.

Matsuzaki, K., Murase, O., Tokuda, H., Funakoshi, S., Fujii, N., Miyajima, K., 1994. Orientational and Aggregational States of Magainin 2 in Phospholipid Bilayers. Biochemistry-Us 33, 3342-3349.

Matsuzaki, K., Sugishita, K., Miyajima, K., 1999. Interactions of an antimicrobial peptide, magainin 2, with lipopolysaccharide-containing liposomes as a model for outer membranes of gram-negative bacteria. FEBS Lett 449, 221-224.

McDermott, A.E., 2009. Structure and Dynamics of Membrane Proteins by Magic Angle Spinning Solid-State NMR. Annu.Rev.Biophys 38, 385-403.

Mendz, G.L., Moore, W.J., Kaplin, I.J., Cornell, B.A., Separovic, F., Miller, D.J., Brown, L.R., 1988. Characterization of dodecylphosphocholine/myelin basic protein complexes. Biochemistry-Us 27, 379-386.

Moreau, C., Cavalier, A., Le Floch, M., Segalen, J., Rocher, C., Traikia, M., Leray, G., Bondon, A., Thomas, D., Le Rumeur, E., 2001. Sarcolemma phospholipid structure investigated by immunogold electron microscopy and P-31 NMR spectroscopy with lanthanide ions. Febs Letters 509, 417-422.

Nicolas, P., 2009. Multifunctional host defense peptides: intracellular-targeting antimicrobial peptides. FEBS J 276, 6483-6496.

Nielsen, J.T., Bjerring, M., Jeppesen, M.D., Pedersen, R.O., Pedersen, J.M., Hein, K.L., Vosegaard, T., Skrydstrup, T., Otzen, D.E., Nielsen, N.C., 2009. Unique identification of supramolecular structures in amyloid fibrils by solid-state NMR spectroscopy. Angew.Chem Int.Ed Engl. 48, 2118-2121.

Nieuwkoop, A.J., Rienstra, C.M., 2010. Supramolecular protein structure determination by site-specific long-range intermolecular solid state NMR spectroscopy. J Am Chem Soc 132, $7570-7571$.

North, C.L., Barranger-Mathys, M., Cafiso, D.S., 1995. Membrane orientation of the Nterminal segment of alamethicin determined by solid-state 15 N NMR. Biophys.J. 69, 23922397.

Ottiger, M., Bax, A., 1998. Characterization of magnetically oriented phospholipid micelles for measurement of dipolar couplings in macromolecules. J Biomol.NMR 12, 361-372.

Ouellet, M., Doucet, J.D., Voyer, N., Auger, M., 2007. Membrane topology of a 14-mer model amphipathic peptide: a solid-state NMR spectroscopy study. Biochemistry-Us 46, 6597-6606.

Ouellet, M., Voyer, N., Auger, M., 2010. Membrane interactions and dynamics of a 21-mer cytotoxic peptide: A solid-state NMR study. Bba-Biomembranes 1798, 235-243. 
Oyston, P.C., Fox, M.A., Richards, S.J., Clark, G.C., 2009. Novel peptide therapeutics for treatment of infections. J Med Microbiol 58, 977-987.

Ozdirekcan, S., Etchebest, C., Killian, J.A., Fuchs, P.F., 2007. On the orientation of a designed transmembrane peptide: toward the right tilt angle? J Am.Chem Soc. 129, 1517415181.

Pabst, G., Grage, S.L., nner-Pongratz, S., Jing, W., Ulrich, A.S., Watts, A., Lohner, K., Hickel, A., 2008. Membrane thickening by the antimicrobial peptide PGLa. Biophys J 95, 5779-5788.

Padovan, L., Scocchi, M., Tossi, A., 2010. Structural aspects of plant antimicrobial peptides. Curr Protein Pept Sci 11, 210-219.

Palermo, E.F., Kuroda, K., 2010. Structural determinants of antimicrobial activity in polymers which mimic host defense peptides. Appl Microbiol Biotechnol 87, 1605-1615.

Park, T.J., Kim, J.S., Choi, S.S., Kim, Y., 2009. Cloning, expression, isotope labeling, purification, and characterization of bovine antimicrobial peptide, lactophoricin in Escherichia coli. Protein Expres Purif 65, 23-29.

Patch, J.A., Barron, A.E., 2003. Helical peptoid mimics of magainin-2 amide. J Am.Chem.Soc. 125, 12092-12093.

Patti, G.J., Kim, S.J., Yu, T.Y., Dietrich, E., Tanaka, K.S.E., Parr, T.R., Far, A.R., Schaefer, J., 2009. Vancomycin and Oritavancin Have Different Modes of Action in Enterococcus faecium. J Mol Biol 392, 1178-1191.

Pauli, J., van Rossum, B., Forster, H., de Groot, H.J., Oschkinat, H., 2000. Sample optimization and identification of signal patterns of amino acid side chains in 2D RFDR spectra of the alpha-spectrin SH3 domain. Journal of Magnetic Resonance 143, 411-416.

Picard, F., Paquet, M.J., Dufourc, E.J., Auger, M., 1998. Measurement of the lateral diffusion of dipalmitoylphosphatidylcholine adsorbed on silica beads in the absence and presence of melittin: a 31P two-dimensional exchange solid-state NMR study. Biophys J 74, 857-868.

Picard, F., Paquet, M.J., Levesque, J., Belanger, A., Auger, M., 1999. 31P NMR first spectral moment study of the partial megnetic orientation of phospholipid membranes. Biophys.J. 77, 888-892.

Pieters, R.J., Arnusch, C.J., Breukink, E., 2009. Membrane permeabilization by multivalent anti-microbial peptides. Protein Pept Lett 16, 736-742.

Porcelli, F., Buck, B., Lee, D.K., Hallock, K.J., Ramamoorthy, A., Veglia, G., 2004. Structure and orientation of pardaxin determined by NMR experiments in model membranes. J Biol Chem 279, 45815-45823.

Porter, E.A., Weisblum, B., Gellman, S.H., 2002. Mimicry of host-defense peptides by unnatural oligomers: antimicrobial beta-peptides. J Am Chem Soc 124, 7324-7330.

Pott, T., Dufourc, E.J., 1995. Action of melittin on the DPPC-cholesterol liquid-ordered phase: a solid state $2 \mathrm{H}$-and $31 \mathrm{P}-\mathrm{NMR}$ study. Biophys.J. 68, 965-977.

Pott, T., Maillet, J.C., Abad, C., Campos, A., Dufourcq, J., Dufourc, E.J., 2001. The lipid charge density at the bilayer surface modulates the effects of melittin on membranes. Chem Phys Lipids 109, 209-223.

Pott, T., Paternostre, M., Dufourc, E.J., 1998. A comparative study of the action of melittin on sphingomyelin and phosphatidylcholine bilayers. Eur.Biophys.J. 27, 237-245. 
Pouny, Y., Rapaport, D., Mor, A., Nicolas, P., Shai, Y., 1992. Interaction of antimicrobial dermaseptin and its fluorescently labeled analogues with phospholipid membranes.

Biochemistry-Us 31, 12416-12423.

Prestegard, J.H., 1998. New techniques in structural NMR - anisotropic interactions. Nature Structural Biology, NMR Supplement, 517-522.

Prongidi-Fix, L., Bertani, P., Bechinger, B., 2007. The membrane alignment of helical peptides from non-oriented $15 \mathrm{~N}$ chemical shift solid-state NMR spectroscopy. J.Am.Chem.Soc. 129, 8430-8431.

Prosser, R.S., Davis, J.H., 1994. Dynamics of an integral membrane peptide: a deuterium NMR relaxation study of gramicidin. Biophys.J. 66, 1429-1440.

Raimondo, D., Andreotti, G., Saint, N., Amodeo, P., Renzone, G., Sanseverino, M., Zocchi, I., Molle, G., Motta, A., Scaloni, A., 2005. A folding-dependent mechanism of antimicrobial peptide resistance to degradation unveiled by solution structure of distinctin. Proc Natl Acad Sci U S A 102, 6309-6314.

Ramamoorthy, A., 2009. Beyond NMR spectra of antimicrobial peptides: dynamical images at atomic resolution and functional insights. Solid State Nucl Magn Reson. 35, 201-207.

Ramamoorthy, A., Lee, D.K., Narasimhaswamy, T., Nanga, R.P., 2009. Cholesterol reduces pardaxin's dynamics-a barrel-stave mechanism of membrane disruption investigated by solidstate NMR. Biochim Biophys Acta.

Ramamoorthy, A., Lee, D.K., Narasimhaswamy, T., Nanga, R.P.R., 2010. Cholesterol reduces pardaxin's dynamics-a barrel-stave mechanism of membrane disruption investigated by solid-state NMR. Bba-Biomembranes 1798, 223-227.

Ramamoorthy, A., Lee, D.K., Santos, J.S., Henzler-Wildman, K.A., 2008. Nitrogen-14 solidstate NMR spectroscopy of aligned phospholipid bilayers to probe peptide-lipid interaction and oligomerization of membrane associated peptides. J Am.Chem Soc. 130, 11023-11029.

Ramamoorthy, A., Thennarasu, S., Lee, D.K., Tan, A., Maloy, L., 2006. Solid-state NMR investigation of the membrane-disrupting mechanism of antimicrobial peptides MSI-78 and MSI-594 derived from magainin 2 and melittin. Biophys.J. 91, 206-216.

Ramamoorthy, A., Wei, Y., Lee, D., 2004. PISEMA Solid-State NMR Spectroscopy. Annual Reports on NMR Spectroscopy 52, 1-52.

Reddy, K.V., Yedery, R.D., Aranha, C., 2004. Antimicrobial peptides: premises and promises. Int J Antimicrob Agents 24, 536-547.

Renault, M., Saurel, O., Demange, P., Reat, V., Milon, A., 2010. Solution-state NMR spectroscopy of membrane proteins in detergent micelles: structure of the Klebsiella pneumoniae outer membrane protein A, KpOmpA. Methods Mol Biol 654, 321-339.

Resende, J.M., Mendonca Moraes, C., Munhoz, V.H.D.O., Aisenbrey, C., Verly, R.M., Bertani, P., Cesar, A., Pilo-Veloso, D., Bechinger, B., 2009. Membrane structure and conformational changes during bilayer-association of the antibiotic heterodimeric peptide distinctin by oriented solid-state NMR spectroscopy. Proc.Natl.Acad.Sci.U.S.A 106, 1663916644.

Romo, T.D., Bradney, L.A., Greathouse, D.V., Grossfield, A., 2011. Membrane binding of an acyl-lactoferricin B antimicrobial peptide from solid-state NMR experiments and molecular dynamics simulations. Bba-Biomembranes 1808, 2019-2030. 
Rotem, S., Mor, A., 2009. Antimicrobial peptide mimics for improved therapeutic properties. Biochim Biophys Acta 1788, 1582-1592.

Salnikov, E., Aisenbrey, C., Balandin, S.V., Zhmak, M.N., Ovchinnikova, A.Y., Bechinger, B., 2011. Structure and alignment of the membrane-associated antimicrobial peptide arenicin by oriented solid-state NMR spectroscopy. Biochemistry-Us 50, 3784-3795.

Salnikov, E., Aisenbrey, C., Vidovic, V., Bechinger, B., 2010a. Solid-state NMR approaches to measure topological equilibria and dynamics of membrane polypeptides. Biochim. Biophys. Acta 1798, 258-265.

Salnikov, E., Bechinger, B., 2011. Lipid-mediated peptide-peptide interactions in bilayers: Structural insights into the synergistic enhancement of the antimicrobial activities of PGLa and magainin 2. Biophysical J. 100, 1473-1480.

Salnikov, E., Bertani, P., Raap, J., Bechinger, B., 2009a. Analysis of the amide (15)N chemical shift tensor of the C(alpha) tetrasubstituted constituent of membrane-active peptaibols, the alpha-aminoisobutyric acid residue, compared to those of di- and trisubstituted proteinogenic amino acid residues. J Biomol NMR 45, 373-387.

Salnikov, E., Rosay, M., Pawsey, S., Ouari, O., Tordo, P., Bechinger, B., 2010b. Solid-state NMR spectroscopy of oriented membrane polypeptides at $100 \mathrm{~K}$ with signal enhancement by dynamic nuclear polarization. J Am Chem Soc 132, 5940-5941.

Salnikov, E.S., Friedrich, H., Li, X., Bertani, P., Reissmann, S., Hertweck, C., O'Neil, J.D., Raap, J., Bechinger, B., 2009b. Structure and alignment of the membrane-associated peptaibols ampullosporin A and alamethicin by oriented $15 \mathrm{~N}$ and $31 \mathrm{P}$ solid-state NMR spectroscopy. Biophys.J. 96, 86-100.

Salnikov, E.S., Mason, A.J., Bechinger, B., 2009c. Membrane order perturbation in the presence of antimicrobial peptides by $2 \mathrm{H}$ solid-state NMR spectroscopy. Biochimie 91, 743.

Sanders II, C.R., Hare, B.J., Howard, K.P., Prestegard, J.H., 1994. Magnetically-Oriented Phospholipid Micelles as a Tool for the Study of Membrane-Associated Molecules. Progress in NMR Spectroscopy 26, 421-444.

Sani, M.A., Keech, O., Gardestrom, P., Dufourc, E.J., Grobner, G., 2009. Magic-angle phosphorus NMR of functional mitochondria: in situ monitoring of lipid response under apoptotic-like stress. Faseb J 23, 2872-2878.

Sansom, M.S., 1993. Alamethicin and related peptaibols--model ion channels. Eur.Biophys.J. 22, 105-124.

Savjani, J.K., Gajjar, A.K., Savjani, K.T., 2009. Mechanisms of resistance: useful tool to design antibacterial agents for drug - resistant bacteria. Mini Rev Med Chem 9, 194-205.

Scherer, P.G., Seelig, J., 1989. Electric Charge Effects on Phospholipid Headgroups. Phosphatidycholine in Mixtures with Cationic and Anionic Amphiles. Biochemistry-Us 28, 7720-7727.

Schneider, R., Ader, C., Lange, A., Giller, K., Hornig, S., Pongs, O., Becker, S., Baldus, M., 2008. Solid-state NMR spectroscopy applied to a chimeric potassium channel in lipid bilayers. J Am.Chem Soc. 130, 7427-7435.

Schuetz, A., Wasmer, C., Habenstein, B., Verel, R., Greenwald, J., Riek, R., Bockmann, A., Meier, B.H., 2010. Protocols for the Sequential Solid-State NMR Spectroscopic Assignment of a Uniformly Labeled 25 kDa Protein: HET-s(1-227). Chembiochem. 
Schweizer, F., 2009. Cationic amphiphilic peptides with cancer-selective toxicity. Eur J Pharmacol 625, 190-194.

Scott, R.W., DeGrado, W.F., Tew, G.N., 2008. De novo designed synthetic mimics of antimicrobial peptides. Curr Opin Biotechnol 19, 620-627.

Seelig, J., 1977. Deuterium magnetic resonance: theory and application to lipid membranes. Q.Rev.Biophys 10, 353-418.

Seelig, J., 1978. 31P nuclear magnetic resonance and the head group structure of phospholipids in membranes. Biochim Biophys Acta 515, 105-140.

Seelig, J., Seelig, A., 1980. Lipid conformation in model membranes and biological membranes. Q.Rev.Biophys 13, 19-61.

Seidel, K., Andronesi, O.C., Krebs, J., Griesinger, C., Young, H.S., Becker, S., Baldus, M., 2008. Structural characterization of $\mathrm{Ca}(2+)$-ATPase-bound phospholamban in lipid bilayers by solid-state nuclear magnetic resonance (NMR) spectroscopy. Biochemistry-Us 47, 43694376.

Shai, Y., 1999. Mechanism of the binding, insertion, and destabilization of phospholipid bilayer membranes by alpha-helical antimicrobial and cell non-selective lytic peptides. Biochimica et Biophysica Acta 1462, 55-70.

Sherman, P.J., Jackway, R.J., Gehman, J.D., Praporski, S., McCubbin, G.A., Mechler, A., Martin, L.L., Separovic, F., Bowie, J.H., 2009. Solution Structure and Membrane Interactions of the Antimicrobial Peptide Fallaxidin 4.1a: An NMR and QCM Study. Biochemistry-Us 48, 11892-11901.

Steinstraesser, L., Kraneburg, U., Jacobsen, F., Al-Benna, S., 2010. Host defense peptides and their antimicrobial-immunomodulatory duality. Immunobiology.

Strandberg, E., Esteban-Martin, S., Salgado, J., Ulrich, A.S., 2009a. Orientation and dynamics of peptides in membranes calculated from 2H-NMR data. Biophys J 96, 3223-3232.

Strandberg, E., Kanithasen, N., Tiltak, D., Burck, J., Wadhwani, P., Zwernemann, O., Ulrich, A.S., 2008. Solid-state NMR analysis comparing the designer-made antibiotic MSI-103 with its parent peptide PGLa in lipid bilayers. Biochemistry-Us 47, 2601-2616.

Strandberg, E., Ozdirekcan, S., Rijkers, D.T., Van Der Wel, P.C., Koeppe, R.E., Liskamp, R.M., Killian, J.A., 2004. Tilt angles of transmembrane model peptides in oriented and nonoriented lipid bilayers as determined by 2H solid-state NMR. Biophys J 86, 3709-3721.

Strandberg, E., Tremouilhac, P., Wadhwani, P., Ulrich, A.S., 2009b. Synergistic transmembrane insertion of the heterodimeric PGLa/magainin 2 complex studied by solidstate NMR. Biochim Biophys Acta 1788, 1667-1679.

Strandberg, E., Wadhwani, P., Tremouilhac, P., Durr, U.H., Ulrich, A.S., 2006. Solid-state NMR analysis of the PGLa peptide orientation in DMPC bilayers: structural fidelity of $2 \mathrm{H}-$ labels versus high sensitivity of 19F-NMR. Biophys J 90, 1676-1686.

Straus, S.K., Scott, W.R., Watts, A., 2003. Assessing the effects of time and spatial averaging in $15 \mathrm{~N}$ chemical shift/15N-1H dipolar correlation solid state NMR experiments. J Biomol NMR 26, 283-295.

Su, Y.C., Hong, M., 2011. Conformational Disorder of Membrane Peptides Investigated from Solid-State NMR Line Widths and Line Shapes. Journal of Physical Chemistry B 115, 1075810767. 
Su, Y.C., Waring, A.J., Ruchala, P., Hong, M., 2011. Structures of beta-Hairpin Antimicrobial Protegrin Peptides in Lipopolysaccharide Membranes: Mechanism of Gram Selectivity Obtained from Solid-State Nuclear Magnetic Resonance. Biochemistry-Us 50, 2072-2083.

Sudheendra, U.S., Bechinger, B., 2005. Topological equilibria of ion channel peptides in oriented lipid bilayers revealed by $15 \mathrm{~N}$ solid-state NMR spectroscopy. Biochemistry-Us 44 , 12120-12127.

Sugewara, M., Resende, J.M., Moraes, C.M., Metz-Boutigue, M.H., Bechinger, B., 2009. Structure and interactions in membranes of human and bovine Catestatin by solution and solid-state NMR spectroscopy. in preparation.

Sugewara, M., Resende, J.M., Moraes, C.M., Metz-Boutigue, M.H., Bechinger, B., 2010. Structure and interactions in membranes of human and bovine Catestatin by solution and solid-state NMR spectroscopy. Faseb J 24, 1737-1746

Takei, J., Remenyi, A., Dempsey, C.E., 1999. Generalised bilayer perturbation from peptide helix dimerisation at membrane surfaces: vesicle lysis induced by disulphide- dimerised melittin analogues. FEBS Letters 442, 11-14.

Tang, M., Hong, M., 2009. Structure and mechanism of beta-hairpin antimicrobial peptides in lipid bilayers from solid-state NMR spectroscopy. Mol Biosyst 5, 317-322.

Tang, M., Waring, A.J., Lehrer, R.I., Hong, M., 2006. Orientation of a beta-hairpin antimicrobial peptide in lipid bilayers from two-dimensional dipolar chemical-shift correlation NMR. Biophys J 90, 3616-3624.

Thennarasu, S., Tan, A., Penumatchu, R., Shelburne, C.E., Heyl, D.L., Ramamoorthy, A., 2010. Antimicrobial and membrane disrupting activities of a peptide derived from the human cathelicidin antimicrobial peptide LL37. Biophys J 98, 248-257.

Thogersen, L., Schiott, B., Vosegaard, T., Nielsen, N.C., Tajkhorshid, E., 2008. Peptide aggregation and pore formation in a lipid bilayer: a combined coarse-grained and all atom molecular dynamics study. Biophys.J. 95, 4337-4347.

Traaseth, N.J., Buffy, J.J., Zamoon, J., Veglia, G., 2006. Structural dynamics and topology of phospholamban in oriented lipid bilayers using multidimensional solid-state NMR.

Biochemistry-Us 45, 13827-13834.

Traaseth, N.J., Shi, L., Verardi, R., Muller, D., Barany, G., Veglia, G., 2009. Structure and topology of monomeric phospholamban in lipid membranes determined by a hybrid solution and solid-state NMR approach. Proc.Natl.Acad.Sci.USA 106, 10165-10170.

Traikia, M., Warschawski, D.E., Recouvreur, M., Cartaud, J., Devaux, P.F., 2000. Formation of unilamellar vesicles by repetitive freeze-thaw cycles: characterization by electron microscopy and P-31-nuclear magnetic resonance. Eur Biophys J Biophy 29, 184-195.

Tremouilhac, P., Strandberg, E., Wadhwani, P., Ulrich, A.S., 2006. Conditions affecting the re-alignment of the antimicrobial peptide PGLa in membranes as monitored by solid state $2 \mathrm{H}$ NMR. Biochim Biophys Acta 1758, 1330-1342.

Triba, M.N., Warschawski, D.E., Devaux, P.F., 2005. Reinvestigation by phosphorus NMR of lipid distribution in bicelles. Biophys J 88, 1887-1901.

Triba, M.N., Zoonens, M., Popot, J.L., Devaux, P.F., Warschawski, D.E., 2006.

Reconstitution and alignment by a magnetic field of a beta-barrel membrane protein in bicelles. Eur.Biophys J 35, 268-275. 
Varga, K., Tian, L., McDermott, A.E., 2007. Solid-state NMR study and assignments of the KcsA potassium ion channel of S. lividans. Biochim Biophys Acta 1774, 1604-1613.

Verardi, R., Traaseth, N.J., Shi, L., Porcelli, F., Monfregola, L., De Luca, S., Amodeo, P., Veglia, G., Scaloni, A., 2011. Probing membrane topology of the antimicrobial peptide distinctin by solid-state NMR spectroscopy in zwitterionic and charged lipid bilayers. BbaBiomembranes 1808, 34-40.

Verly, R.M., Moraes, C.M., Resende, J.M., Aisenbrey, C., Bemquemer, M.P., Pilo-Veloso, D., Valente, A.P., Alemida, F.C., Bechinger, B., 2009. Structure and membrane interactions of the antibiotic peptide dermadistinctin $\mathrm{k}$ by solution and oriented $15 \mathrm{~N}$ and $31 \mathrm{P}$ solid-state NMR spectroscopy. Biophys.J. 96, 2194-2202.

Vermeer, L.S., de Groot, B.L., Reat, V., Milon, A., Czaplicki, J., 2007. Acyl chain order parameter profiles in phospholipid bilayers: computation from molecular dynamics simulations and comparison with H-2 NMR experiments. Eur Biophys J Biophy 36, 919-931.

Vidovic, V., 2010. Overexpression and purification of the transfection peptide LAH4 and the biophysical investigations of its complex with DNA using NMR spectroscopy. PhD thesis (in preparation).

Violette, A., Fournel, S., Lamour, K., Chaloin, O., Frisch, B., Briand, J.P., Monteil, H., Guichard, G., 2006. Mimicking helical antibacterial peptides with nonpeptidic folding oligomers. Chem. Biol. 13, 531-538.

Vogt, T.C.B., Bechinger, B., 1999. The interactions of histidine-containing amphipathic helical peptide antibiotics with lipid bilayers: The effects of charges and $\mathrm{pH}$. J Biol Chem 274, 29115-29121.

Vogt, T.C.B., Ducarme, P., Schinzel, S., Brasseur, R., Bechinger, B., 2000. The topology of lysine-containing amphipathic peptides in bilayers by CD, solid-state NMR and molecular modelling. Biophys.J. 79, 2644-2656.

Vold, R.R., Prosser, R.S., Deese, A.J., 1997. Isotropic solutions of phospholipid bicelles: a new membrane mimetic for high-resolution NMR studies of polypeptides. J Biomol NMR 9, 329-335.

Vooturi, S.K., Firestine, S.M., 2010. Synthetic membrane-targeted antibiotics. Curr Med Chem 17, 2292-2300.

Vosegaard, T., Kamihira-Ishijima, M., Watts, A., Nielsen, N.C., 2008. Helix conformations in 7TM membrane proteins determined using oriented-sample solid-state NMR with multiple residue-specific 15N labeling. Biophys J 94, 241-250.

Vostrikov, V.V., Hall, B.A., Greathouse, D.V., Koeppe, R.E., 2nd, Sansom, M.S., 2010. Changes in transmembrane helix alignment by arginine residues revealed by solid-state NMR experiments and coarse-grained MD simulations. J Am Chem Soc 132, 5803-5811.

Watts, A., 2005. Solid-state NMR in drug design and discovery for membrane-embedded targets. Nat.Rev.Drug Discov. 4, 555-568.

Wenk, M., Seelig, J., 1998. Magainin 2 amide interaction with lipid membranes: Calorimetric detection of peptide binding and pore formation. Biochemistry-Us 37, 3909-3916.

Westerhoff, H.V., Juretic, D., Hendler, R.W., Zasloff, M., 1989. Magainins and the disruption of membrane-linked free-energy transduction. Proc Natl Acad Sci U S A 86, 6597-6601.

Westerhoff, H.V., Zasloff, M., Rosner, J.L., Hendler, R.W., de Waal, A., Vaz, G., Jongsma, P.M., Riethorst, A., Juretic, D., 1995. Functional synergism of the magainins PGLa and 
magainin-2 in Escherichia coli, tumor cells and liposomes. European Journal of Biochemistry $228,257-264$.

Wi, S., Kim, C., 2008. Pore structure, thinning effect, and lateral diffusive dynamics of oriented lipid membranes interacting with antimicrobial peptide protegrin-1: P-31 and $\mathrm{H}-2$ solid-state NMR study. Journal of Physical Chemistry B 112, 11402-11414.

Wieprecht, T., Apostolov, O., Seelig, J., 2000. Binding of the antibacterial peptide magainin 2 amide to small and large unilamellar vesicles. Biophys Chem EDAT- 2000/08/29 MHDA2000/08/29 PST - ppublish 85, 187-198.

Wieprecht, T., Beyermann, M., Seelig, J., 1999. Binding of antibacterial magainin peptides to electrically neutral membranes: Thermodynamics and structure. Biochemistry-Us 38, 1037710378.

Williamson, P.T., Bains, S., Chung, C., Cooke, R., Watts, A., 2002. Probing the environment of neurotensin whilst bound to the neurotensin receptor by solid state NMR. FEBS Lett. 518, 111-115.

Wray, V., Kinder, R., Federau, T., Henklein, P., Bechinger, B., Schubert, U., 1999. Solution structure and orientation of the transmembrane anchor domain of the HIV-1 encoded virus protein $\mathrm{U}(\mathrm{Vpu})$ by high-resolution and solid-state NMR spectroscopy. Biochemistry-Us 38, 5272-5282.

Xu, J., Soong, R., Im, S.C., Waskell, L., Ramamoorthy, A., 2010. INEPT-Based SeparatedLocal-Field NMR Spectroscopy: A Unique Approach To Elucidate Side-Chain Dynamics of Membrane-Associated Proteins. J Am Chem Soc.

Zairi, A., Tangy, F., Bouassida, K., Hani, K., 2009. Dermaseptins and magainins: antimicrobial peptides from frogs' skin-new sources for a promising spermicides microbicides-a mini review. J Biomed Biotechnol 2009, 452567.

Zasloff, M., 1987. Magainins, a class of antimicrobial peptides from Xenopus skin: Isolation, characterization of two active forms, and partial cDNA sequence of a precursor. Proc.Natl.Acad.Sci.USA 84, 5449-5453.

Zasloff, M., 2002. Antimicrobial peptides of multicellular organisms. Nature 415, 389-395.

Zhang, L., Falla, T.J., 2010. Potential therapeutic application of host defense peptides. Methods Mol Biol 618, 303-327.

Zhendre, V., Grelard, A., Garnier-LHomme, M., Buchoux, S., Larijani, B., Dufourc, E.J., 2011. Key Role of Polyphosphoinositides in Dynamics of Fusogenic Nuclear Membrane Vesicles. PLoS One 6. 


\section{FIGURE CAPTIONS}

Figure 1: Proton-decoupled ${ }^{15} \mathrm{~N}$ solid-state NMR spectrum of 2 mole $\%{ }^{15} \mathrm{~N}-\mathrm{Ala}{ }^{14} \mathrm{PGLa}$ in uniaxially oriented POPC bilayers recorded at room temperature.

Figure 2: Analysis of the PGLa topologies, assuming a perfect $\alpha$-helix $\left(\varphi=-58^{\circ}, \psi=-47^{\circ}\right)$. The tilt and rotational pitch angular pairs that agree with a ${ }^{15} \mathrm{~N}$ chemical shift of the $\mathrm{Ala}^{14}$ position of $90 \pm 4$ ppm (cf. Fig. 1) are shown as solid red lines. The dashed black traces show the topologies that agree with a quadrupolar splitting of $\left[\mathrm{C}^{2} \mathrm{H}_{3}-\mathrm{Ala}^{10}\right]-\mathrm{PGLa}$ in oriented phosphatidylcholine membranes in the range $(15 \pm 2.5) \mathrm{kHz}$ (Strandberg et al., 2006). The topological analysis assuming a fixed topology is shown in panel A, whereas the effect of motions around the azimuthal angle and wagging fluctuations of the helix long axis within Gaussian angle distributions of $15^{\circ}$ and $17^{\circ}$, respectively, are included in the simulations shown in panel B. The circle shows the topological overlap between the two curves closes to the value that has been obtained from taking into account nine ${ }^{2} \mathrm{H}$ orientational restraints ((Strandberg et al., 2006), $\tau=98^{\circ}$ and $\rho=115^{\circ}$ ).

Figure 3: Proton-decoupled ${ }^{31} \mathrm{P}$ solid-state NMR spectra of A. POPC phospholipid bilayers mechanically oriented between glass slides. Also indicated are the resonance positions that correspond to lipids oriented parallel or perpendicular to $B_{0}$. B. Oriented POPC sample after extended storage in the freezer. C. Oriented POPC membrane in the presence of 2 mole \% PGLa D. oriented POPC/POPG 3/1 mole/mole membrane (glass plate normal parallel to the external magnetic field), E. same sample as in D tilted by 90 degrees, and F. POPC/POPG 3/1 multilamellar vesicles. The deconvolution of spectrum was achieved by using ${ }^{31} \mathrm{P}$ chemical shift tensors of (29 ppm, -13.5 ppm, -13.5 ppm; blue dashed line) and (27 ppm, -10.5 ppm, 10.5 ppm; red thin dashed line), which were assigned to be POPC and POPG, respectively, in accordance to the resonance intensities (3:1) and with the help of published chemical shift anisotropies (Seelig, 1978; Sherman et al., 2009). The oriented samples A-D were inserted into the spectrometer with the glass plate normal parallel to the magnetic field direction, whereas sample E was tilted by 90 degrees. All spectra were recorded at room temperature.

Figure 4: A. Molecular model of amphipathic peptide-induced membrane thinning illustrating the geometrical dimensions of the resulting dip structure. B. Simulations of the 
proton-decoupled ${ }^{31} \mathrm{P}$ solid-state NMR spectra when a stack of POPC membranes is supported between lipid glass slides. The spectra are shown for $b=20 \AA, a=24 \AA$ and $d=4 \AA$ at the three different lateral diffusion rates indicated to the left. C. Model of an elliptic torroidal pore in a flat membrane. The elliptic ring torus is characterized by the rotation of an elliptic circle described be the geometric parameters shown in the Figure. $a$ is the radius of the pore at its narrowest location, $b$ is the thickness of the lipid monolayer and $d$ the elliptic semiminor axis. D-F show the resulting ${ }^{31} \mathrm{P}$ NMR line shapes within a supported bilayer for $a=b$ and $d / b=0.5$ (D), 1 (E) and $1.4(\mathrm{~F})$ as a function of lateral diffusion constant (indicated to the right). Only the lipid contributions from the pore or the dip structure, respectively, are shown. Therefore in real samples the contributions from the non-disturbed flat parts of the membrane will make additional, and often pronounced contributions at the 0-degree intensity (close to $30 \mathrm{ppm}$ for phosphatidylcholines in the liquid crystalline state). The Figure is reproduced from (Kim et al., 2009) with kind permission from Sungsool Wi and the publisher.

Figure 5: A. ${ }^{2} \mathrm{H}$ solid-state NMR spectrum of POPC-d $\mathrm{d}_{31} / \mathrm{POPG} 3 / 1 \mathrm{~mole} / \mathrm{mole}$ in the presence (black line) or absence (grey line) of 2 mole\% PGLa. B. Deconvolution of the spectrum shown in A provides position-dependent quadrupolar splittings and the corresponding deuterium order parameters $\mathrm{S}_{\mathrm{CD}}$. As an example the read out of two quadrupolar splittings are shown in panel A and the corresponding order parameters highlighted by arrows in panel B. The PGLa peptide causes a decrease in the POPC- $\mathrm{d}_{31}$ order parameters corresponding to a reduction of the average thickness of the membrane by $0.3 \AA$ (cf. text for details).

Figure 6: Graphical illustrations of the motions that occur in membranes as well as an overview over the characteristic time scales. Peptide helices are represented in blue in a transmembrane (cylinder in the middle) or an in-plane orientation (left cylinder and right circle). See details in the text and the Table 2. 


\section{FIGURES}

Figure 1:

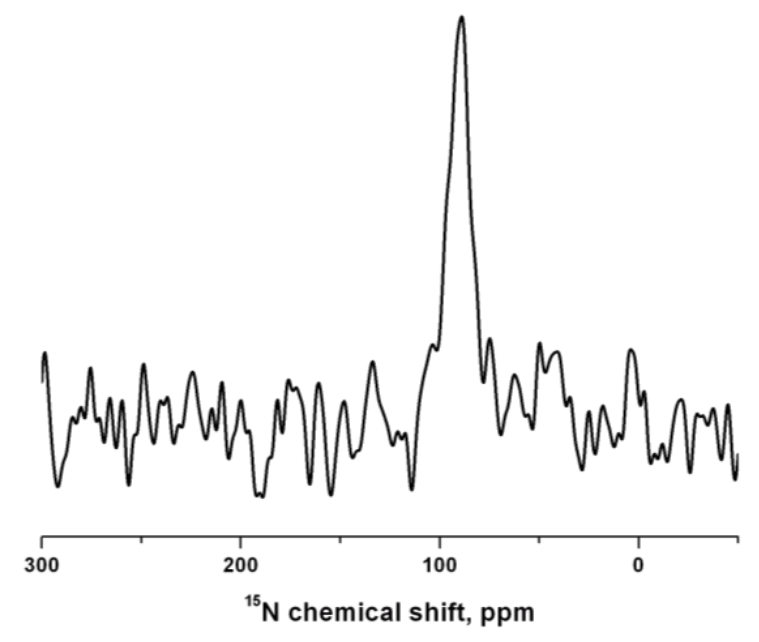

Figure 2:
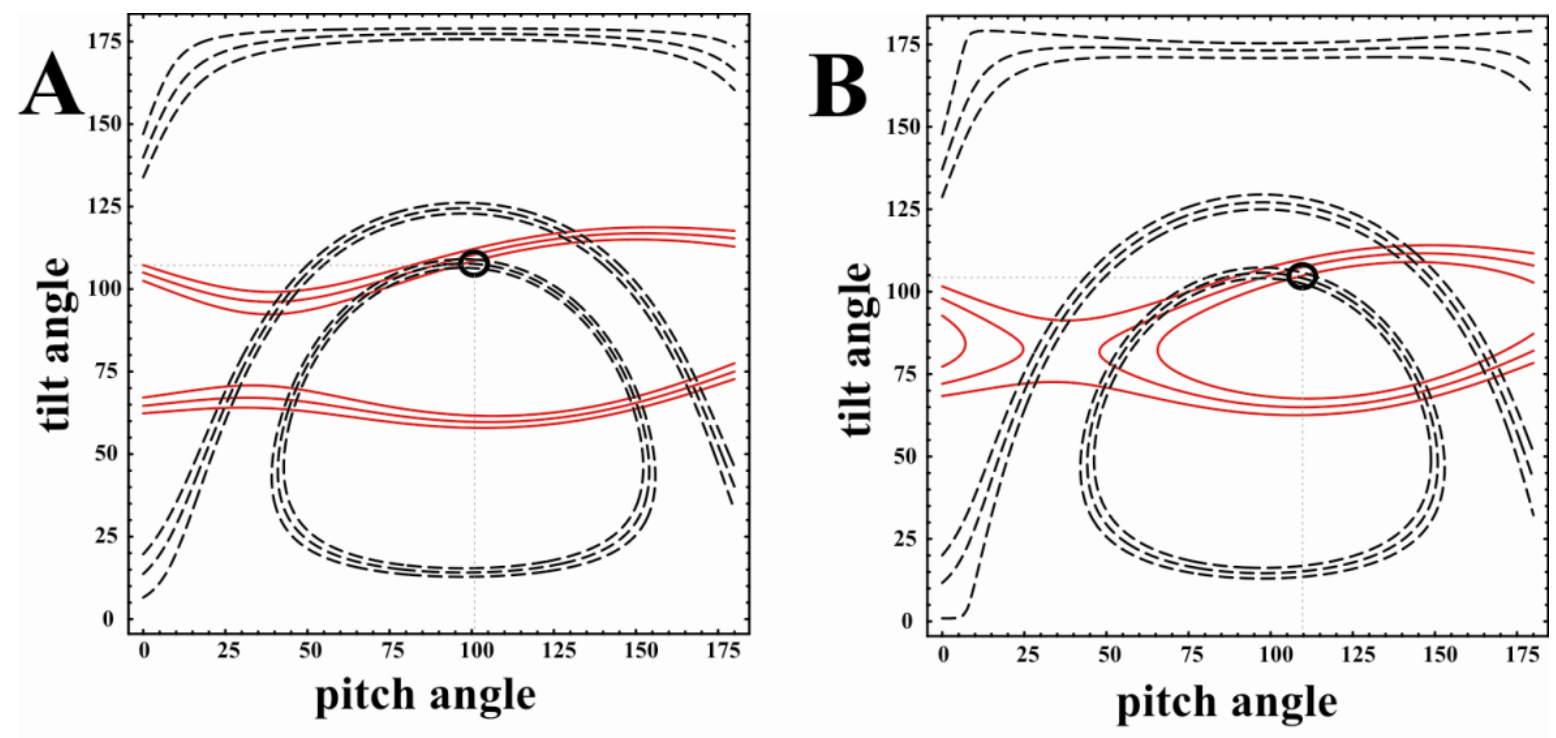
Figure 3:
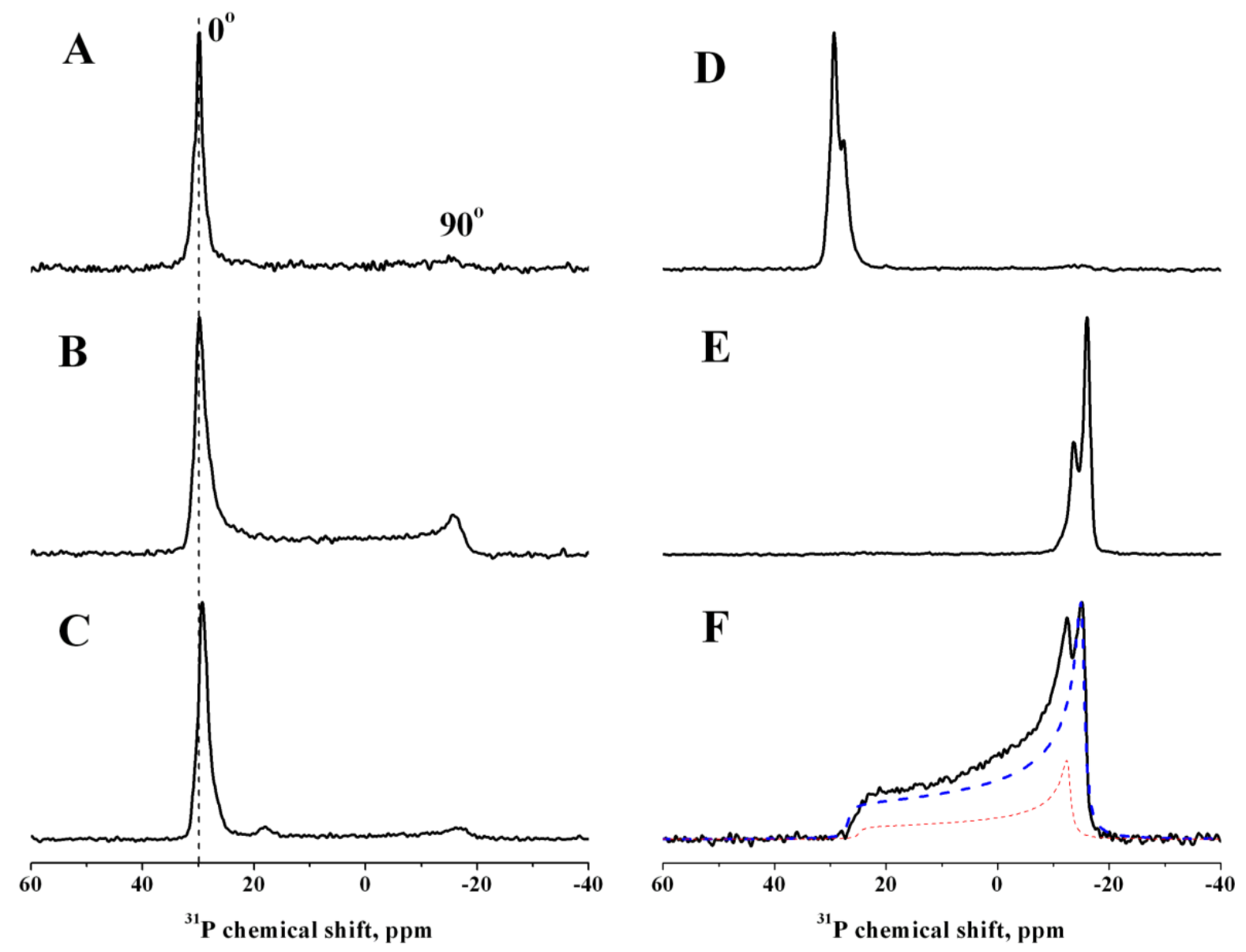
Figure 4:
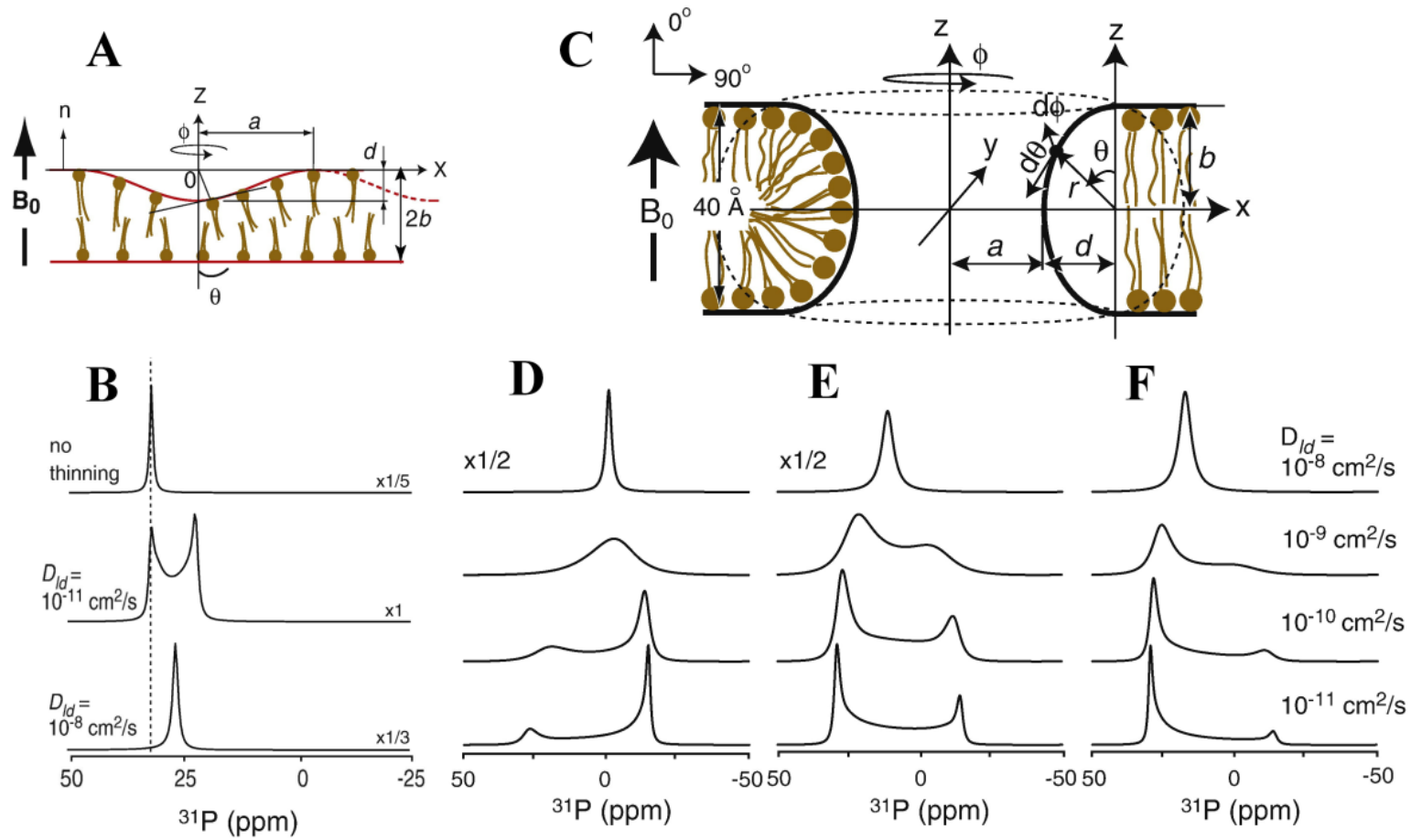

Figure 5:
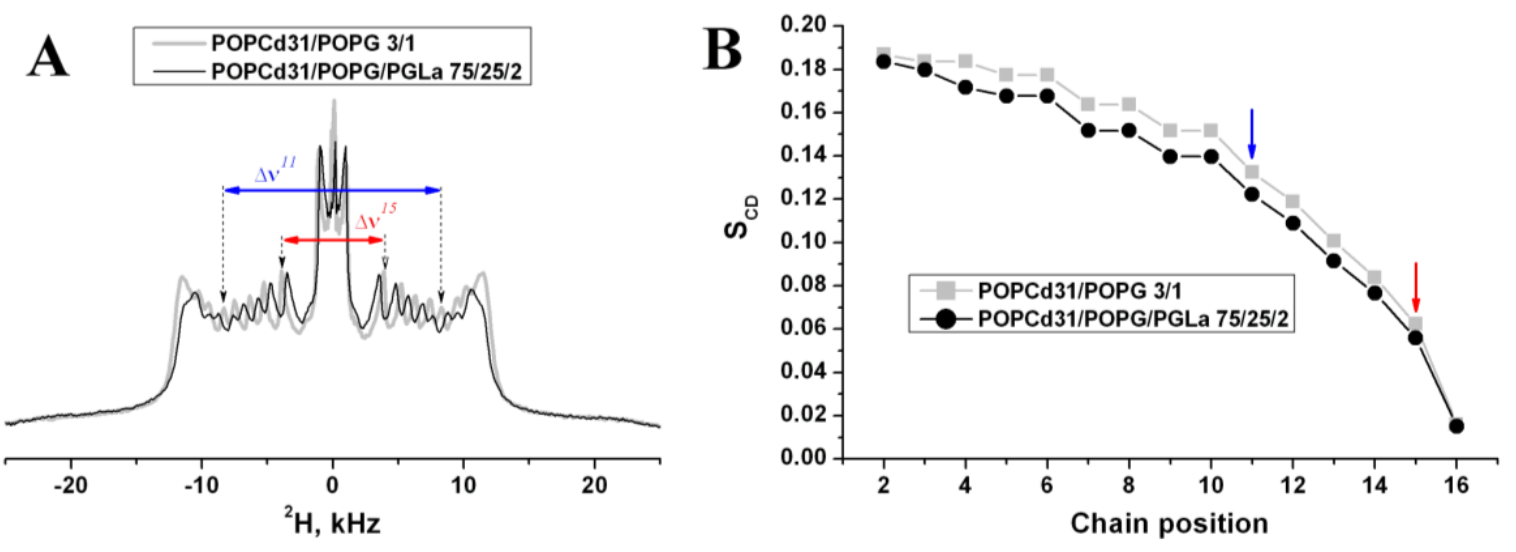
Figure 6:

\begin{tabular}{lllllll}
\hline & $10^{-12}$ & $10^{-9}$ & $10^{-6}$ & $10^{-3}$ & 1 & $10^{+3}$
\end{tabular}

Bond rotation, small angle librations, etc.

Membrane deformation

Fusion

\begin{tabular}{|l|l|}
\hline Molecular diffusion & Topological transitions \\
\hline
\end{tabular}

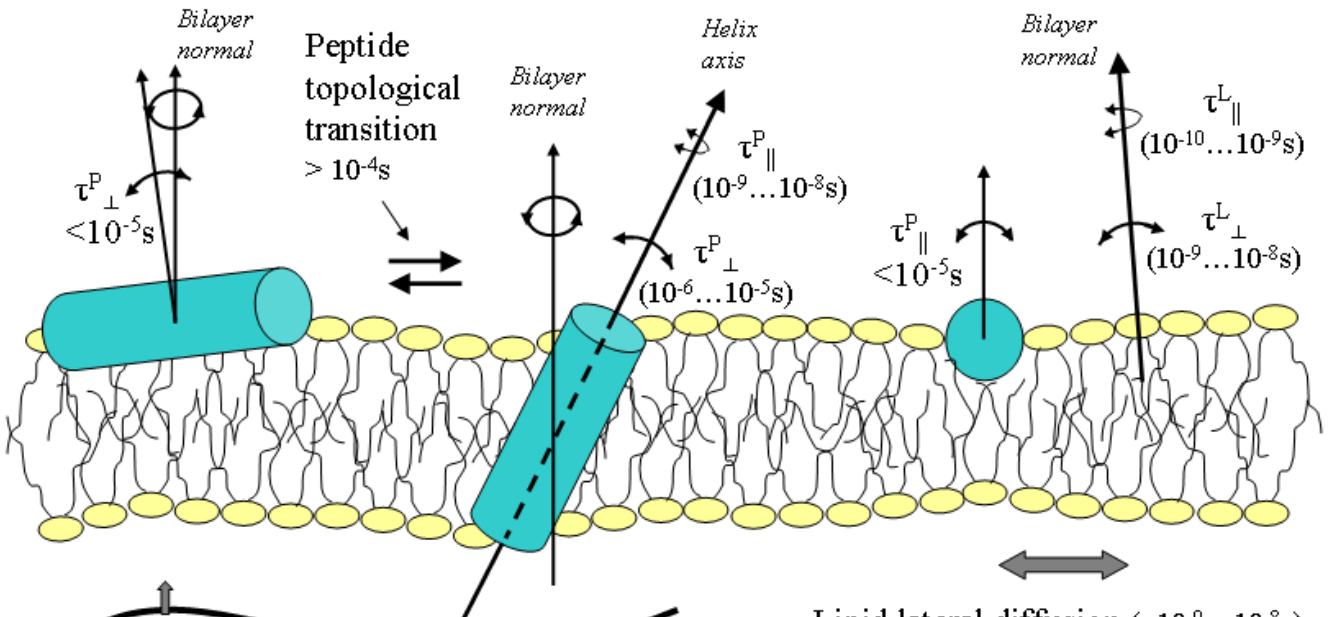

Lipid lateral diffusion $\left(\sim 10^{-9} \ldots 10^{-8} \mathrm{~s}\right)$

'Ondulations' $\left(10^{-9} \ldots 10^{-3} \mathrm{~s}\right)$ 